Please do not remove this page

RMIT

UNIVERSITY

\title{
A review of toroidal composite pressure vessel optimisation and damage tolerant design for high pressure gaseous fuel storage
}

Fowler, Calum; Orifici, Adrian; Wang, Chun

https://researchrepository.rmit.edu.au/esploro/outputs/9921861798801341/filesAndLinks?institution=61RMIT_INST\&index=null

Fowler, C., Orifici, A., \& Wang, C. (2016). A review of toroidal composite pressure vessel optimisation and damage tolerant design for high pressure gaseous fuel storage. International Journal of Hydrogen Energy, 41(47), 22067-22089. https://doi.org/10.1016/j.ijhydene.2016.10.039

Document Version: Accepted Manuscript

Published Version: https://doi.org/10.1016/j.ijhydene.2016.10.039

Repository homepage: https://researchrepository.rmit.edu.au

(C) 2016 Elsevier

Downloaded On 2023/04/26 19:46:04 +1000 
Thank you for downloading this document from the RMIT Research Repository.

The RMIT Research Repository is an open access database showcasing the research outputs of RMIT University researchers.

RMIT Research Repository: http://researchbank.rmit.edu.au/

\section{Citation:}

Fowler, C, Orifici, A and Wang, C 2016, 'A review of toroidal composite pressure vessel optimisation and damage tolerant design for high pressure gaseous fuel storage', International Journal of Hydrogen Energy, vol. 41, no. 47, pp. 22067-22089.

See this record in the RMIT Research Repository at:

https://researchbank.rmit.edu.au/view/rmit:40032

Version: Accepted Manuscript

Copyright Statement: ‘ 2016 Elsevier

Link to Published Version:

http://www.sciencedirect.com/science/article/pii/S0360319916330336 
A review of toroidal composite pressure vessel optimisation and damage tolerant design for high pressure gaseous fuel storage

\author{
Calum P. Fowler ${ }^{1}$, Adrian C. Orifici ${ }^{1}$, and Chun H. Wang ${ }^{2 *}$ \\ ${ }^{I}$ School of Engineering, RMIT University, GPO Box 2476, Melbourne VIC 3001, Australia \\ ${ }^{2}$ School of Mechanical and Manufacturing Engineering, University of New South Wales, Sydney, NSW 2052, Australia
}

\begin{abstract}
On-board high-pressure storage of hydrogen gas and compressed natural gas is critical to the widespread adoption of alternative gaseous fuel to reduce $\mathrm{CO}_{2}$ emissions in transportation. Cylindrical pressure vessels are the traditional option for on-board gaseous fuel storage; however they possess domed heads that are prone to over-design and a source of manufacturing difficulties. Toroidal composite pressure vessels (CPV) have been recognised as a volumetrically efficient solution that could address these problems, thus reducing vessel mass, while improving storage efficiencies. Currently, there exist many gaps in toroidal CPV research which must be addressed to fully realise the potential of this technology. Herein we present a comprehensive and critical review of the design and optimisation of toroidal CPVs, focusing on damage tolerant design as a key requirement to meet safety standards and optimisation of toroidal cross-sectional profiles (shape, thickness variation and fibre winding pattern) to reduce or eliminate stress non-uniformity. An original analysis of toroidal radius ratio $(R / r)$ influence on the thickness profiles of naturally-thickened and isotensoid circular toroidal CPVs is conducted. It is concluded that a focus on smaller radius ratios $(1.25<R / r<3)$ is required to maximise the potential spacesaving and volumetric efficiencies of the torus. Leading international CPV standards are analysed in order to adapt three important design qualification requirements from cylindrical to toroidal structures. Building block approaches are also presented to aid the damage tolerant design of toroidal CPVs for the relevant design qualification tests.
\end{abstract}

Keywords: Toroidal pressure vessel; composite pressure vessel; damage tolerant design; hydrogen storage; compressed natural gas storage

\begin{tabular}{cl}
\hline \multicolumn{1}{c}{ Nomenclature } \\
\hline$p$ & Internal pressure $[\mathrm{MPa}]$ \\
\hline$V$ & Internal volume $\left[\mathrm{m}^{3}\right]$ \\
\hline$R$ & Toroidal centreline radius $[\mathrm{mm}]$ \\
\hline$r$ & Cross-sectional radius [mm] \\
\hline$\varphi$ & Hoop angle $\left[^{\circ}\right]$ \\
\hline$\vartheta$ & Axial angle $\left[{ }^{\circ}\right]$ \\
\hline$\alpha$ & Winding angle $\left[{ }^{\circ}\right]$ \\
\hline$\alpha_{A}$ & Winding angle at location $\mathbf{A}\left(\varphi=0^{\circ}\right)\left[{ }^{\circ}\right]$ \\
\hline$t$ & Shell thickness [mm] \\
\hline$t_{A}$ & Shell thickness at location $\mathbf{A}\left(\varphi=0^{\circ}\right)[\mathrm{mm}]$ \\
\hline$t_{B}$ & Shell thickness at location $\mathbf{B}\left(\varphi=90^{\circ}\right)[\mathrm{mm}]$ \\
\hline$t_{\alpha}$ & Shell thickness of composite overwrap from natural thickening [mm] \\
\hline$\sigma_{\varphi}$ & Hoop stress [MPa] \\
\hline$\sigma \vartheta$ & Axial stress [MPa]
\end{tabular}

\title{
1. Introduction
}

Hydrogen $\left(\mathrm{H}_{2}\right)$ and compressed natural gas $(\mathrm{CNG})$ are promising alternative transport fuels that can be utilised to lower greenhouse gas emissions, reduce fuel costs and decrease the dependence on fossil fuels. Natural gas consists mostly of methane and can be found in large reserves across the world. Due to its low volumetric energy density, natural gas is commonly stored in a compressed state in high-pressure storage vessels as $\mathrm{CNG}$, with internal pressures of $20 \mathrm{MPa}$ or more [1]. $\mathrm{H}_{2}$ is another renewable gaseous fuel source and like methane is lighter than air. Current on-board $\mathrm{H}_{2}$ storage tanks have operational pressures up to $35 \mathrm{MPa}$ [2]

\footnotetext{
*Correspondence author: chun.h.wang@unsw.edu.au
} 
however 50-55 MPa has been found to provide the best trade-off between storage pressure and cost effectiveness [3]. CNG and hydrogen can also be stored as cryogenic liquids [4] or as solid fuels by chemically or physically combining with materials such as metal hydrides or high surface area materials such as activated carbon [5]. Sarkar and Banerjee [6] used a net energy analysis technique to compare various storage methods and found that compressed $\mathrm{H}_{2}$ storage had lower energy consumption than the other options. Hydrogen fuel cell and natural gas vehicles have many potential environmental advantages over gasoline and diesel powered vehicles. However, their widespread adoption has yet to be realised due to the limited storage capacities, and therefore limited driving ranges, of gaseous fuel storage tanks [7].

Pressure vessels consisting of cylindrical bodies and domed heads are the traditional option for on-board gaseous fuel storage. However, they can be volumetrically inefficient and possess domed heads that are prone to over-design and a source of manufacturing difficulties [8,9]. Cylindrical pressure vessels can also suffer from stress concentrations in high curvature regions when their cross-sections deviate from traditional circular profiles [10]. This ultimately restricts their design flexibility. Toroidal (donut-shaped) pressure vessels have recently been recognised as a promising alternative solution that would avoid these problems, thus leading to vessel weight reduction, increased volumetric efficiency and higher operational pressures. However, there currently exist many gaps in toroidal pressure vessel research which must be addressed to realise the potential of this energy storage technology.

The present article aims to comprehensively and critically review recent progress on the design and optimisation of toroidal composite pressure vessels (CPV), focusing on damage tolerant design as a key requirement to meet safety standards and optimisation of toroidal cross-sectional profiles (shape, thickness variation and fibre winding pattern) to reduce or eliminate stress non-uniformity. New contributions that address significant gaps in the literature include (1) an analysis of the influence of radius ratio $(R / r)$ on toroidal vessel thickness profiles pertinent to winding-thickened and isotensoid toroids, (2) the adaptation of design qualification test requirements from cylinders to toroids, and (3) the development of building block approaches to design toroidal CPVs for such tests. Cylindrical storage vessel designs are briefly reviewed first. An overview of toroidal shell theory and toroid-related research is then presented. This leads to a comprehensive review of toroidal CPV research and a critical analysis of existing toroidal CPV geometrical parameters and key parametric relations. Finally, an in-depth review of leading international CPV design standards and subsequent design qualification tests is undertaken so that future research on toroidal CPVs can incorporate damage tolerant design. Significant gaps in the literature are identified throughout the paper and are summarised in the Conclusion section where future research opportunities to address these gaps are identified.

\section{Spherical and cylindrical high pressure gaseous storage tanks}

Internally pressurised vessels have historically utilised spherical or cylindrical shapes due to the fact that spheres experience the lowest membrane stress on their walls compared to any other shape [11] of equal weight. At the present time, hydrogen fuel cell and natural gas vehicles are fitted with cylindrical storage vessels with domed heads that can be made of metal, composites, or a combination of these. These tanks are often fitted into the trunk of a vehicle which is not spatially ideal as other functions such as storage space are compromised, as illustrated in Figure 1a. By contrast, a toroidal vessel shown in Figure 1b offers a more space efficient option.

Several publications including ISO 11439 [12] - an international standard for high pressure on-board CNG storage cylinders - outline four types of cylindrical pressure vessel design which are listed below. Type V vessels are now in existence also but are not yet covered by a standard or code. Five types of design shown in Figure 2 are:

- Type I: Full-metal cylinder with domed heads

- Type II: Metal liner with composite hoop-wrapped reinforcement - metal liner supports $55 \%$ of internal pressure

- Type III: Metal liner with full composite overwrap - overwrap carries up to $80 \%$ of pressure load

- Type IV: Full composite overwrap with non-load bearing, plastic liner (i.e. HDPE) - liner houses gas and acts as a mandrel for filament winding process

- Type V: Liner-less vessel with a full composite shell. 

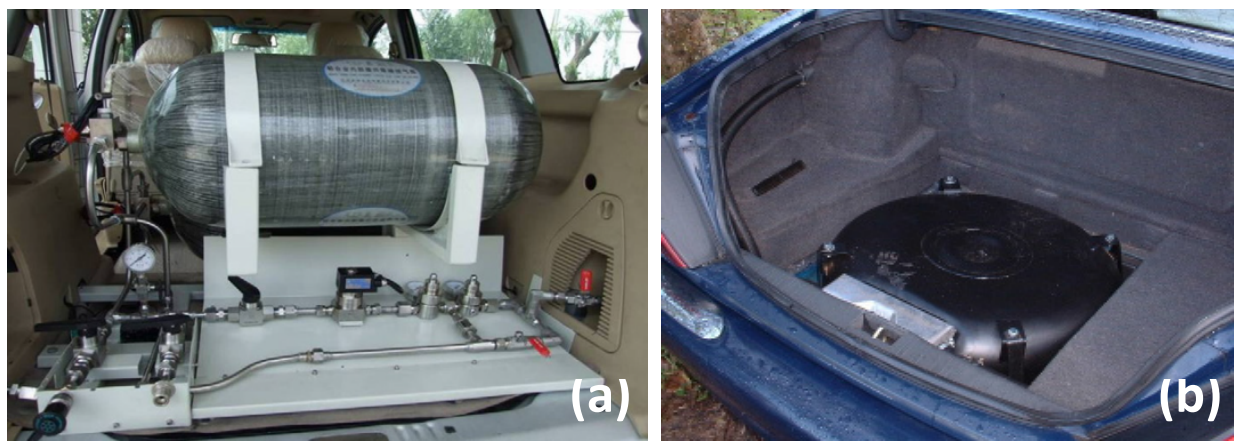

Figure 1: (a) A composite $\mathrm{H}_{2}$ fuel tank installed in the trunk of a $\mathrm{H}_{2}$ fuel cell vehicle [13]; (b) a metallic toroidal LPG fuel tank installed in the spare tire cavity of a retrofitted vehicle trunk [14]

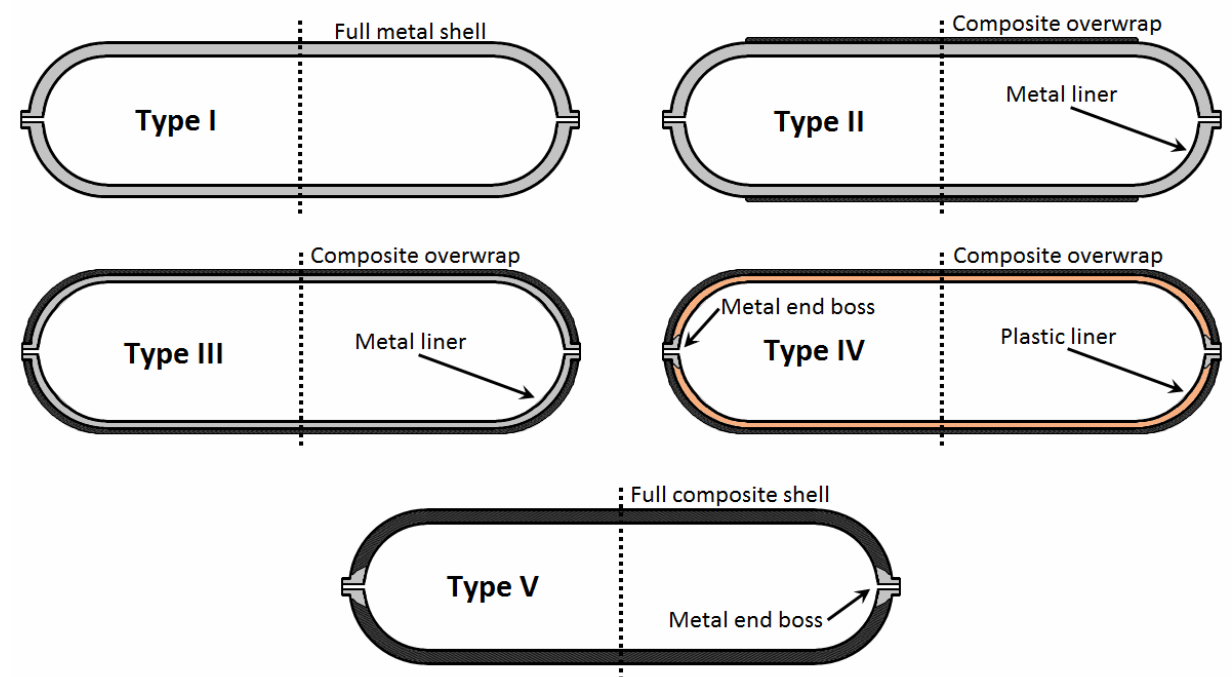

Figure 2: Five types of pressure vessel for on-board gaseous fuel storage - Types I-IV are outlined in ISO11439:2013; Type V is not currently covered by a standard or code (figure adapted from [12])

Gas used in industrial applications is traditionally stored in Type I cylindrical tanks as they are the least expensive however they are the heaviest. Type II tanks are more commonly used when high pressures are required for stationary applications. They are lighter than Type I tanks but are more expensive. Type III-V tanks are utilised for portable applications where light weight is essential [4]. Composite overwraps of these vessels generally consist of glass, aramid or carbon fibres. Type IV and V vessels are the lightest of the varieties due to the lack of metallic liners; however they are more expensive due to the greater use of composite materials. The amount of composite material (in kilograms) in Type IV cylindrical vessels has been found to be almost linearly proportional to their hydrogen carrying capacity [15].

A structural performance index $(I)$ is commonly used for rating the storage efficiency of pressure vessels by maximising both internal pressure and internal volume whilst minimising weight. This can be expressed as [1618]:

$$
I=\frac{p_{\text {burst }} \cdot V}{W}
$$

where $p_{\text {burst }}$ is burst pressure, $V$ is internal volume and $W$ is vessel mass. 
The design and optimisation of cylindrical pressure vessels, in particular composite overwrapped vessels, is extensively covered in the literature and will not be repeated here. Readers should refer to Liu et al. [13] and Zheng et al. [2] for thorough reviews of the research into cylindrical on-board CPVs. However, it should be noted that large amounts of research have been conducted into the optimisation and reinforcement of domed heads [19-23] as they are prone to over-design which adds unnecessary vessel mass [9]. There is also evidence in the literature of dome failure in the presence of significant mid-cylinder flaws in CPVs where failure may initiate [24].

It is critical that high pressure gaseous storage tanks are designed to strictly operate between $-40^{\circ} \mathrm{C}$ and $+80^{\circ} \mathrm{C}$ as per design standard guidelines [12]. These temperature extremes are typically reached during emptying [25] and fast-filling processes [26], respectively. The influence of parameters such as initial starting pressure [27], inlet gas temperature [28], gas flow rate [29], liner material [26] and nozzle diameter [30] on gas temperatures have been comprehensively studied. However the influence of vessel geometry is relatively unknown, with the exception that lower length-to-diameter ratios result in lower gas temperatures inside cylindrical tanks [30]. More research is needed in this area, in particular on potential advantages or disadvantages of toroidal vessel geometry.

\section{Toroidal pressure vessels}

A torus is an axisymmetric shell of revolution created by rotating an arbitrary two-dimensional shape through $360^{\circ}$ around a central axis to form a ring-shaped structure where the cross-sectional shape does not intersect the axis of revolution [31]. The torus has emerged as a promising gaseous fuel tank design due to its space-saving and weight-reducing potential, its lack of structurally inefficient domed heads and the potentially improved protection of the pressure regulator [8]. It is particularly attractive for spaces with limited height and length, for example the spare tire cavities in passenger vehicles, referring to Figure 1b. Cylindrical vessels that fit within available on-board spaces generally possess length-to-width ratios of approximately 1:1.5 to 1:4 [15]. Toroidal vessels are more appropriate in squarer spaces as their length-to-width ratio is 1:1.

The internal volume of a toroidal vessel with a circular cross-sectional profile can be expressed as [31]:

$$
V \equiv 2 \pi^{2} R \cdot r
$$

where $R$ is the centreline radius and $r$ is the cross-sectional radius. These are defined in Figure 3 .

Circular cross-sectional profiles are generally used for cylindrical vessels because the hoop and axial stresses are uniform along the circumference. Deviations from circular cross-sections can be useful in maximising limited design spaces however these have been found to result in higher local stress concentrations, peak hoop stresses and peak torsional shear stresses [10]. By contrast, circular cross-sections are not the most structurally efficient shape for toroidal vessels. This is because of a non-uniform hoop stress distribution present in the vessel walls due to internal pressure, as explained in more detail in Section 4. Because of this phenomenon, there is potential to create innovative and volume efficient toroidal vessel designs through the use of different cross-sectional shapes and/or changing wall thickness.

\subsection{Toroidal pressure vessel parameters}

The naming and identification of toroidal pressure vessel parameters have varied significantly in the literature $[8,31-53]$. These terms are listed in Table 1 along with the appropriate naming and identification conventions adopted in this article. All parameters and locations listed in Table 1 are illustrated in Figure 3 and Figure 4.

Hoop angle $(\varphi)$ is arguably one of the most important toroidal vessel parameters in terms of hoop stress and wall thickness calculations. In the present work, the starting location $\varphi=0^{\circ}$ is defined at the outer equator with an anticlockwise positive direction as shown in Figure 3 and Figure 4 due to the axis of symmetry with regards to hoop stress that exists between the inner and outer equators. All toroidal-related equations referenced from 
the literature have been re-analysed throughout this article so that results are consistent with parameter definitions.

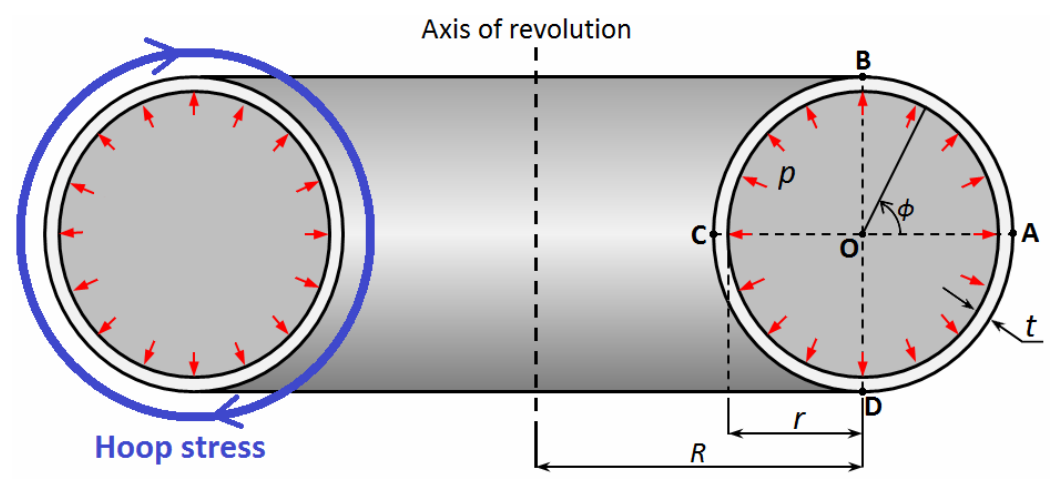

Figure 3: Sectional diagram of a toroidal vessel of circular cross-section (adapted from [33]). All parameters are defined in Table 1

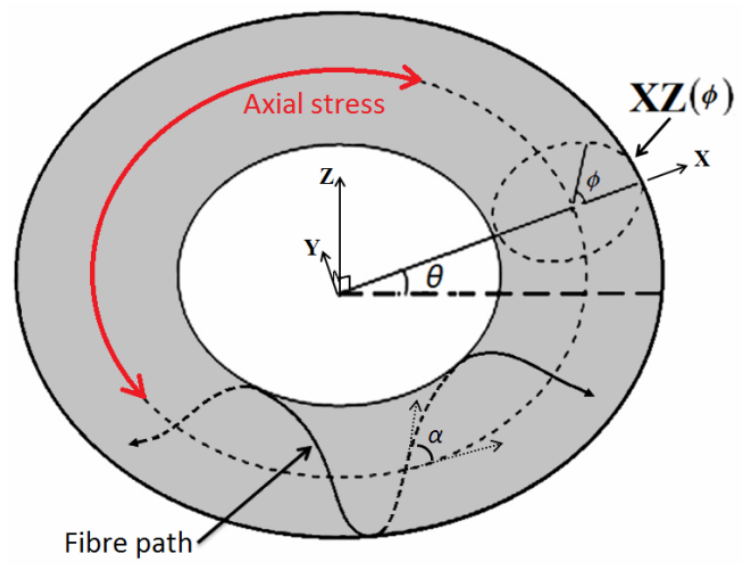

Figure 4: Toroidal filament winding parameters (adapted from [36]). Parameters are listed in Table 1

Table 1: Universal set of identification and naming conventions for toroidal pressure vessel parameters

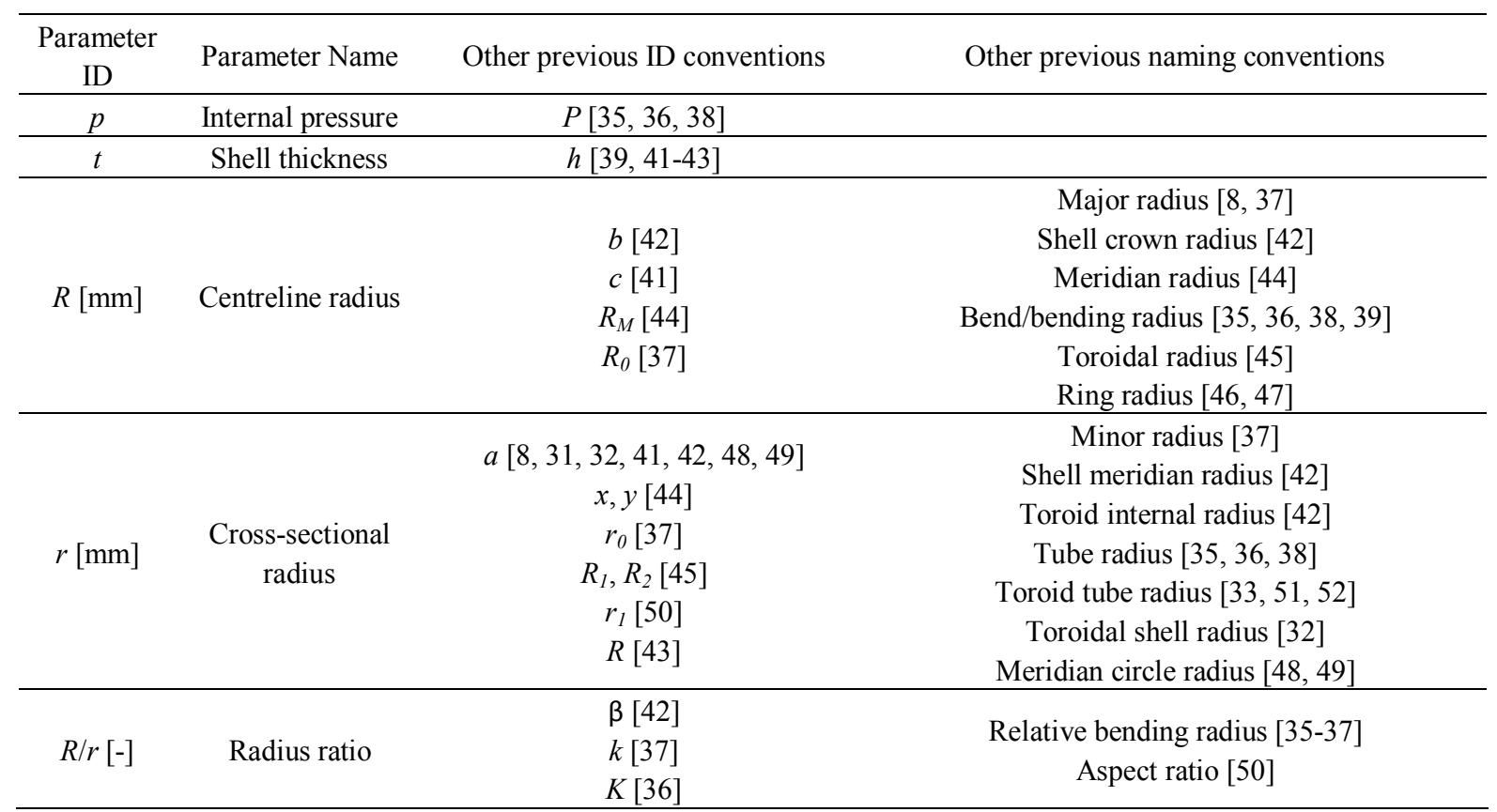




\begin{tabular}{|c|c|c|c|}
\hline & & $\begin{array}{c}a[43,50] \\
\lambda[33]\end{array}$ & \\
\hline$\varphi\left[{ }^{\circ}\right]$ & Hoop angle & $\begin{array}{c}\text { ss }[41] \\
u[37] \\
\vartheta[39] \\
x^{I}[46,47]\end{array}$ & $\begin{array}{c}\text { Material coordinate }[42] \\
\text { Parallel angular coordinate }[36] \\
\text { Meridional angle }[8,31,35-40,50] \\
\text { Meridional coordinate }[33,46,47,52] \\
\text { Co-latitude }[51] \\
\text { Tangential angle }[48,49] \\
\end{array}$ \\
\hline$\theta\left[^{\circ}\right]$ & Axial angle & $\begin{array}{c}\theta \theta[41] \\
v[37] \\
\varphi[39] \\
x^{2}[46,47]\end{array}$ & $\begin{array}{c}\text { Material coordinate }[42] \\
\text { Parallel angle }[35-38] \\
\text { Circumferential angle }[8,31,39,40] \\
\text { Circumferential coordinate }[46,47] \\
\text { Meridian rotational angle }[48,49]\end{array}$ \\
\hline$\alpha\left[^{\circ}\right]$ & Winding angle & $\begin{array}{c}b[8] \\
\beta[44]\end{array}$ & $\begin{array}{c}\text { Ply angle [8] } \\
\text { Wrap angle [44] } \\
\text { Fibre trajectory [37] }\end{array}$ \\
\hline $\begin{array}{c}\text { B, D } \\
\text { (Figure 3) }\end{array}$ & $\begin{array}{c}\text { Poles } \\
\text { (upper/lower) }\end{array}$ & & $\begin{array}{c}\text { Crown (for upper pole) [31] } \\
\text { Flanks }[40] \\
\text { Crests }[8,37,50]\end{array}$ \\
\hline $\begin{array}{c}\text { A, } \mathbf{C} \\
\text { (Figure 3) }\end{array}$ & $\begin{array}{c}\text { Equators } \\
\text { (inner/outer) }\end{array}$ & & $\begin{array}{c}\text { Inner/outer radii }[50] \\
\text { Inside/outside }[8,31,42,48] \\
\text { Inside/outside surfaces }[41] \\
\text { Intrados/extrados }[39,40] \\
\text { Equatorial periphery (for outer radius) [38] } \\
\text { Inner/outer peripheries }[35,38] \\
\text { Inner ring (for inner radius) }[45] \\
\text { Inner/outer equatorial planes [51] }\end{array}$ \\
\hline $\mathbf{X Z}(\varphi)$ & $\begin{array}{l}\text { Cross-sectional } \\
\text { plane }\end{array}$ & & Meridian $[8,31,33,36-38,41,44,48-50,52,53]$ \\
\hline
\end{tabular}

\subsection{Toroidal shell theory}

The use of toroidal vessels for high pressure gaseous fuel storage may be relatively new but studies on toroidal shell theory are well advanced. Linear membrane theory has been used to study the stresses in thinwalled toroidal shells under internal pressure on many occasions. Membrane theory can be applied if a given shell experiences zero or negligible bending deformation [54] so the membrane normal and shear forces can then be assumed to be uniformly distributed through the thickness of the shell. However, several early studies discovered a displacement discontinuity at the upper pole (B - Figure 3) of pressurised toroidal shells when linear membrane theory was used. This has been visually represented by Geuskens et al. [50], as shown in Figure 5, which led to numerous investigations and solutions for isotropic toroidal shells including approximate and simplified non-linear solutions [43, 55], linear and non-linear displacement solutions of elastic [56-60] and hyperelastic [47] toroidal membranes, altering the cross-section of the toroidal shell to avoid bending and nonlinear membrane theories [61], the use of displacement form equations for slender symmetrical toroidal shells [32] and modified linear and non-linear finite element solutions [62]. Readers are directed to Ruggiero et al. [63] for a more in-depth review of this sub-topic.

As the present study is primarily focussed on toroidal CPVs, orthotropic toroidal solutions are of greater concern - several of which have been given in [31, 41, 50]. Maksimyuk and Chernyshenko [41] studied the nonlinear elastic state of thin-walled orthotropic toroidal shells under internal pressure by assuming that the fibre direction and transverse direction stresses in each individual layer of the composite shell were uniform. More recently, a modified linear membrane formulation for orthotropic axisymmetric shells was developed to assess multitorus shells - an interesting hybrid-toroidal vessel concept [50], where it was mentioned that linear membrane solutions for pressurised toroids might be possible if variable stiffness distributions (which can be achieved with the use of fibre-reinforced materials) were used to ensure the deformed cross-sections remain identical to the originals. Li and Cook [31] took a simpler approach and argued that the membrane shell theory was justified for their analysis of Type III toroidal CPVs because (1) the bending moments at the poles of 
toroidal structures are usually negligible for thin toroidal shells and (2) the poles are not the most critically stressed locations around toroidal vessel cross-sections. These justifications seem reasonable so long as toroidal CPVs can be confidently categorised as adhering to thin-wall criteria $(r / t>10)$. It seems that displacement discontinuities are impossible to avoid in isotropic toroidal pressure vessel analysis when linear membrane theory is used. Various techniques have been used to avoid this problem but such methods are difficult to implement. Interestingly, this issue could be overcome when toroidal CPVs utilise fibre-reinforced materials to adjust stiffness distributions. Therefore, assumptions and equations derived from linear membrane theory are generally suitable for the analysis of toroidal CPVs.

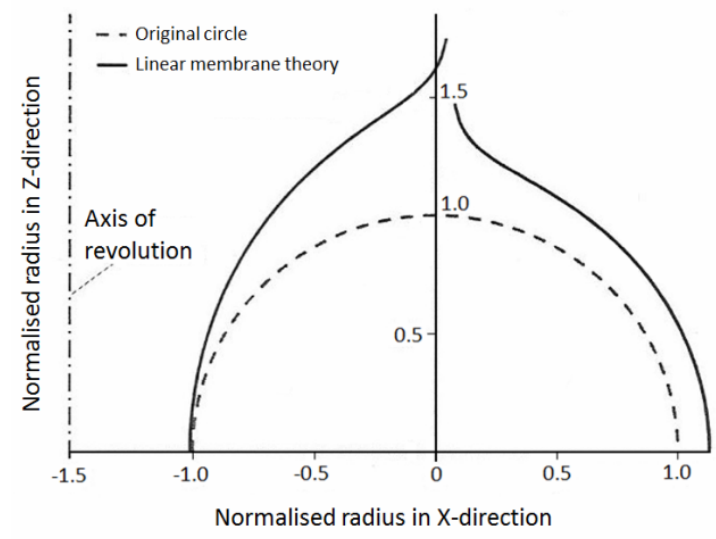

Figure 5: Deformed cross-section with displacement discontinuity of a pressurised isotropic toroidal shell with uniform thickness using linear membrane theory [50]

\subsection{Other toroidal vessel-related research}

Other toroidal vessel-related concepts such as buckling, stability and vibration behaviour have also been investigated in the literature. Differential quadrature method, which converts differential equations of shells to sets of linear simultaneous equations, has been employed in the stability and vibration analysis of isotropic and orthotropic toroidal shells with uniform and variable thicknesses [39, 64-73]. This particular sub-topic of toroidal vessels is outside the scope of this study so it will not be elaborated on further. Readers may consult the work of Ruggiero et al. [63] for a more comprehensive analysis.

While not directly related to toroidal CPV optimisation, the buckling, plastic stability and failure of isotropic toroidal shells $[51,52,74,75]$ is important with regard to the behaviour of vessel liners during pressurisation (internal pressure) and pre-tensioned filament winding processes (external pressure). Elliptical toroidal shells have been predicted to be much stronger than circular shells in terms of buckling under external pressure while both circular and optimised elliptical toroidal shells are less sensitive to initial geometric imperfections under external pressure compared to existing shell geometries (i.e. cylinders, hemispheres) [75]. Like metallic toroids, buckling pressures were found to increase when elliptical cross-sections were utilised in carbon fibre composite toroidal vessels with $[0 / \pm 60]_{\mathrm{s}}$ stacking sequences [76]. Variable wall thickness was also observed to increase buckling pressures. Overall, vessel failure was dictated by buckling failure except for thicker toroids $(r / t=20)$ which were predicted to experience material failure (assuming first ply failure) when $R / r \leq 1.9$. This knowledge is quite useful if toroidal CPVs are designed for applications such as deep-sea scuba diving.

Pressurisation of other various isotropic toroidal vessels has also been studied including the burst failure prediction of thin-walled LPG tanks [45], elastic-plastic failure analysis of thin toroidal shells [77], creep life behaviour of toroidal vessels with various degrees of ovality [78] and shell stress analysis of thick-walled, elastic-perfectly plastic toroidal shells [40]. Toroidal LPG tanks studied by Kisioglu [45] contained oval crosssections that allowed the vessels to have reduced height and therefore possess better space-saving potential than circular equivalents. However, LPG tanks operate at much lower internal pressures (less than $3.45 \mathrm{MPa}$ ) than those needed for hydrogen and CNG storage. This allows for greater flexibility of cross-sectional geometry without excessive weight penalties due to much thinner vessel walls. This also minimises the composite material 
usage on vessel mass reduction. In a separate study [78], increases to ovality were observed to cause lower failure pressures due to localised stress concentrations which develop at the sharper curves of the oval. It is clear from the above that oval cross-sections should be used with caution in toroidal vessel design. A more extensive review of cross-sectional shape optimisation of toroidal vessels is given in Section 4.1.

\subsection{Composite toroidal vessel manufacturing}

Type II-V pressure vessels generally have their composite overwraps applied via filament winding techniques where the filament tow is wound around the vessel liner which acts as a mandrel. The filaments are coated in a thermoset or thermoplastic resin before winding (wet winding) or infused with the resin once winding is completed (dry winding) [79]. The vessel then undergoes a curing process at room temperature or at elevated temperature in an autoclave.

Toroidal winding is more complex than classical cylindrical winding due to the need to feed the filaments through the central hole of the torus [31]. In toroidal winding - the mandrel rotates in a horizontal plane and its rotation is driven by friction rollers that closely contact the outer section of the mandrel. The resultant winding angle $\left([ \pm \alpha]_{n}\right)$ is dictated by the velocities of both the mandrel and feed eye ring. The feed eye of the winding machine rotates in an intersecting plane perpendicular to the mandrel causing the fibre to always make contact at a tangent to the mandrel surface. A schematic of this process is shown in Figure 6, where $P$ is the contact point between the surface of the mandrel and the free-hanging fibre, $r_{\text {ring }}$ is the feed eye ring radius, $\vec{r}_{\phi}$ is a directional derivative which represents the direction of the tangent line between the feed eye and the contact point with respect to $\varphi,{ }^{\omega_{\text {ring }}}$ is the angular velocity of the feed eye ring and $\Phi$ is the rotation angle of the mandrel with respect to the static coordinate system (O-XYZ) where $\mathrm{O}-\mathrm{XZ}$ is the feed eye motion plane. The moving coordinate system that is attached to the mandrel is labelled as $\mathrm{O}-\mathrm{xyz}$, where the $\mathrm{Z}$-axis overlaps the rotational $\mathrm{Z}$ axis [36].

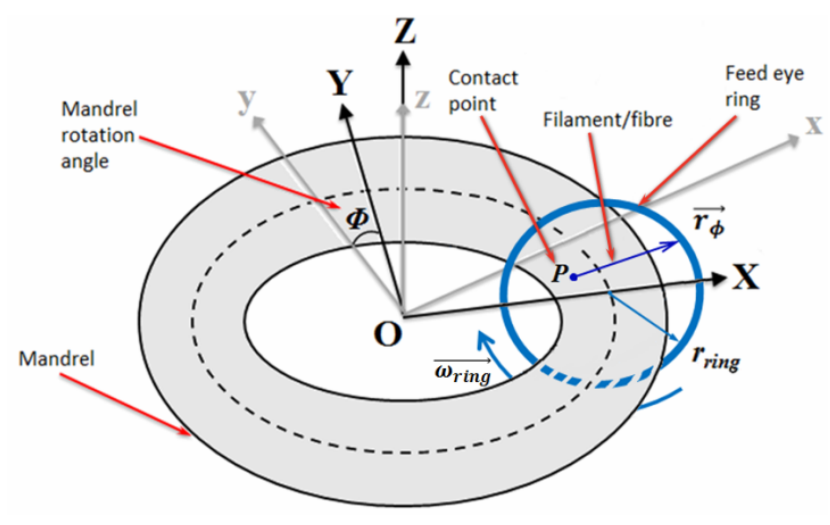

Figure 6: Schematic of a toroidal filament winding process with an associated coordinate system (adapted from [36])

Similar principles apply to both classical and toroidal winding such as ensuring that fibres do not slip from the mandrel surface and over-winding tension does not cause compressive buckling and collapse of the liner [79]. There are also conditions that are exclusive to toroidal winding that must be considered such as fibre bridging which occurs on concave surfaces when fibres lose contact with the mandrel surface due to winding tension [80]. The degree of fibre bridging is largely dictated by the radius ratio $(R / r)$ of the toroidal structure in combination with the winding angle $(\varphi)$ and can be avoided by ensuring that the normal curvature of the fibre path given by Euler formulation is negative [35].

Given that toroidal CPVs are an emerging concept, there are currently only a limited number of toroidal filament winding machines in operation around the world [35, 81-83], partially limiting the extent of research performed on the optimisation and operation of such machines. The most advanced study in this area was performed by $\mathrm{Zu}$ et al. [36] who determined the transmission ratio and kinematic solutions of a novel toroidal winding machine. The study by $\mathrm{Zu}$ et al. aimed to match the required structure-dictated number of wound circuits (i.e. shell thickness) to Diophantine equation solutions for the necessary winding velocities of both the 
mandrel and the feed eye ring. The creation of a dedicated CAD system to calculate optimal fibre patterns and to determine toroidal winder kinematic simulations was proposed to extend the work, however no reports could be located in the literature on this development. Further research in this area would significantly advance the current state-of-the-art and likely improve industrial commercialisation. Cylindrical and toroidal CPV manufacturing efficiencies are both limited by the same factors - winding velocities, number of simultaneous winding heads and resin tack. The key difference currently lies in the cost of the winding machines themselves because toroidal winders must be custom-made due to the relative immaturity of the concept.

\subsection{Location of openings}

The location of openings (i.e. inlet/outlet valves) in toroidal pressure vessels is a topic that has not been widely addressed in the literature. This is likely due to the limited amount of previous research in this field as well as the highly numerical and analytical nature of the research to date. According to a variety of current pressure vessel standards, openings in cylindrical vessels are only permitted in their domed heads and their centreline must coincide with the longitudinal axis of the cylinder [12, 84, 85]. For Type II-IV vessels, openings must also be integrated into metallic bosses that must be made of materials that are compatible with the liner and that do not suffer from stress corrosion cracking (i.e. steel, stainless steel, nickel and aluminium alloys). For toroidal vessels, openings would ideally be located at or near the inner equator so that all valve, pressure regulator and connection components can be protected from accidental impact damage. There is only one instance of this occurring in the experimental literature [45]. Instead, the majority of toroidal vessels tend to have openings located at the poles [35, 51, 52, 86] or at the outer equator [83] of the toroidal cross-section. This was likely done to provide easy access to openings and to avoid placement near maximum hoop-stress locations. The opening position used in [45] requires further investigation in order to fully exploit the space-saving potential of toroidal vessels. Particular attention should be paid to the filament winding arrangement around such discontinuities and the subsequent effects this has on localised thickness increases and the natural thickening effect (discussed in Section 4.2).

\section{Hoop stress variation and design optimisation of toroidal pressure vessels}

The geometry of toroidal structures is primarily determined by their radius ratio $(R / r)$ where toroidal centreline radius $(R)$ and cross-sectional radius $(r)$ are defined in Figure 3. The main effect of $R / r$ on toroidal geometry is that the central hole of toroidal structures increases as $R / r$ increases (Figure 7). It is therefore desirable to keep $R / r$ as small as possible in order to maximise internal volume. However, this leads to an increase in non-uniform hoop stress variation around the cross-sectional profile. A trade-off between these two factors is necessary to achieve the optimum structural efficiency. Surprisingly, little research has been reported on optimising $R / r$ to date which is likely due to industry-related criteria that require toroidal vessels for specific applications (i.e. installation in spare tire cavities) with restricted geometries. The closest that studies have come to $R / r$ optimisation analyses is the work conducted by $\mathrm{Vu}[33,34]$ where various cross-sectional geometry and shell thickness profiles of theoretical toroidal vessels of $R / r=1.25,2.5$ and 5.0 were compared. Unfortunately, the studies were restricted to a limited choice of $R / r$ values. Other $R / r$ values that have been studied in relevant literature vary significantly from a minimum of 1.22 [83] up to 4.71 [44] and 6.0 [40] - with little explanation for the particular choices. The majority of these studies also utilise toroidal vessels with a singular $R / r$ value only. An un-constrained optimisation study is needed to ensure truly optimal $R / r$ values can be obtained for given sets of criteria (i.e. vessel mass, internal volume, burst pressure).

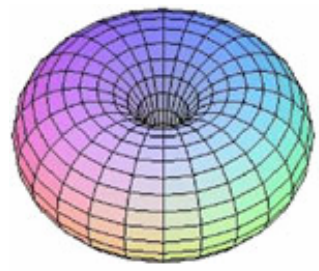

$R / r=1.25$

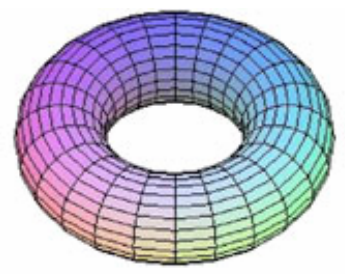

$R / r=2.5$

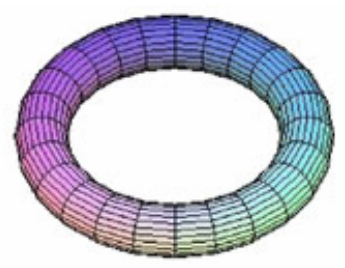

$R / r=5.0$

Figure 7: Toroidal structures of various radius ratio [33] 
Linear membrane shell theory has previously been used to approximate hoop and axial stresses in isotropic toroidal pressure vessels with circular, constant-thickness cross-sections [87]. Hoop stress $\left(\sigma_{\varphi}\right)$ and axial stress $\left(\sigma_{9}\right)$ are defined in Figure 3 and Figure 4Error! Reference source not found. and can be determined using the following equations if thin shell criterion is satisfied $(r / t>10$, formulae only applies away from discontinuities which cause stress concentrations):

$$
\begin{gathered}
\sigma_{\phi}=\frac{p r}{2 t}\left(\frac{2 R+r \cos \phi}{R+r \cos \phi}\right) \\
\sigma_{\theta}=\frac{p r}{2 t}
\end{gathered}
$$

where $R, r, t$ and $\varphi$ are defined in Figure 3. Stress calculations are relatively simple for thin-walled vessels as stresses are assumed to be constant through the thickness which is why they have obtained widespread acceptance. It can be deduced from the above equations that hoop stress varies around the toroidal cross-section and that hoop stress decreases as $R$ (and therefore $R / r$ ) increases. This has been experimentally observed by Blachut [51] who found that toroidal vessels with a small radius ratio $(R / r=2)$ volumetrically expanded in a non-circular manner when internally pressurised however the behaviour became less pronounced for higher radius ratios. On the other hand, axial stress is unaffected by changes to $R$ and is only affected by changes to $r$ and $t$ in terms of geometrical parameters.

Stress analysis of thick-walled vessels becomes considerably more complicated and will not be discussed here. Readers are referred to Sinclair and Helms [88] and Önder [16] for greater depth on this topic along with thick wall formulae for cylindrical vessels. It should be noted that as $t \rightarrow 0$, stresses in thick-wall shells approach the solutions of thin-wall equations.

If shell thickness is assumed to be constant, the hoop stress variation around a circular toroidal cross-section is dictated entirely by $R / r$. The variation in hoop stress between the inner and outer equators $\left(0^{\circ}<\varphi<180^{\circ}\right)$ of toroidal vessels of varying $R / r$ can therefore be calculated using these assumptions and Eqn. 3 (Figure 8). Similar plots have previously been shown by $\mathrm{Vu}$ [33], however $180^{\circ}<\varphi<360^{\circ}$ is not shown here due to symmetry. The $\varphi=0^{\circ}$ position is also different to [33] and a larger range of $R / r$ is utilised here. The hoop stress distribution in Figure 8 becomes significantly more uniform as $R / r$ increases.

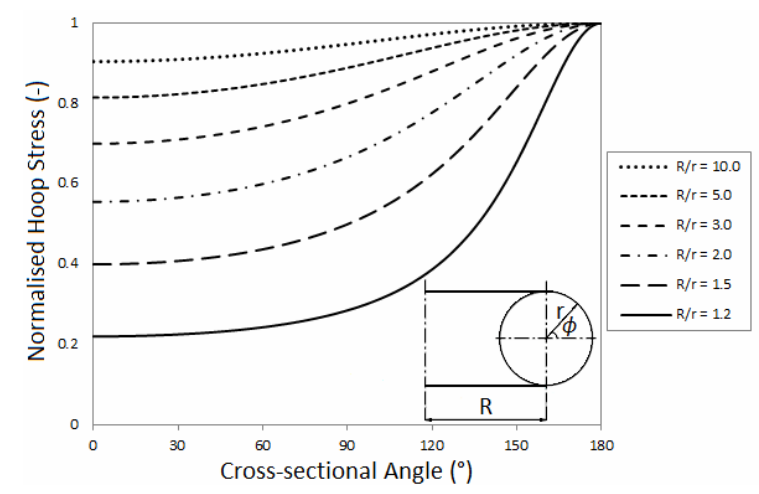

Figure 8: Hoop stress variation around circular constant-thickness toroidal vessels of various radius ratios (normalised with respect to maximum hoop stress values of each individual vessel)

It is clear from the above analysis that the use of circular constant-thickness toroidal vessels provides less than ideal hoop stress distributions unless at very large $R / r$ values. From a theoretical standpoint, the simplest way to avoid this and thus to create a uniform hoop stress distribution is to employ an isotensoid (constant stress) thickness profile. This can be achieved through a simple manipulation of Eqn. 3 (previously performed in [89]) assuming the material is isotropic: 


$$
t_{\phi}=\frac{p r}{2 \sigma_{f}}\left(\frac{2 R+r \cos \phi}{R+r \cos \phi}\right)
$$

where $\sigma_{f}$ denotes the failure strength of the material.

A comparison of isotensoid thickness distributions for toroidal vessels of various $R / r$ reveals that the normalised thickness curves are completely identical in shape to the constant-thickness hoop stress curves of Figure 8 so they are not repeated (i.e. constant thickness $\rightarrow$ varied stress, constant stress $\rightarrow$ varied thickness). A visual comparison of circular and isotensoid thickness profiles for various $R / r$ values is shown in Figure 9. An obvious difference in shape between the cross-sectional thickness profiles in Figure 9 can be observed between the constant and isotensoid thickness profiles at lower $R / r$ values - in particular $R / r=1.2$ - while at larger $R / r$ values the thickness profiles tend to be almost identical due to the higher degree of hoop stress uniformity. There is a significant difference in shell thickness at the outer equator of lower $R / r$ profiles which highlights the potential weight reduction an isotensoid toroidal vessel design can achieve. It should be noted that both constant thickness and isotensoid toroids of $R / r=1.2$ do not fall within thin shell criteria so exact results should be interpreted with caution; general trends in thickness and hoop stress still hold true.
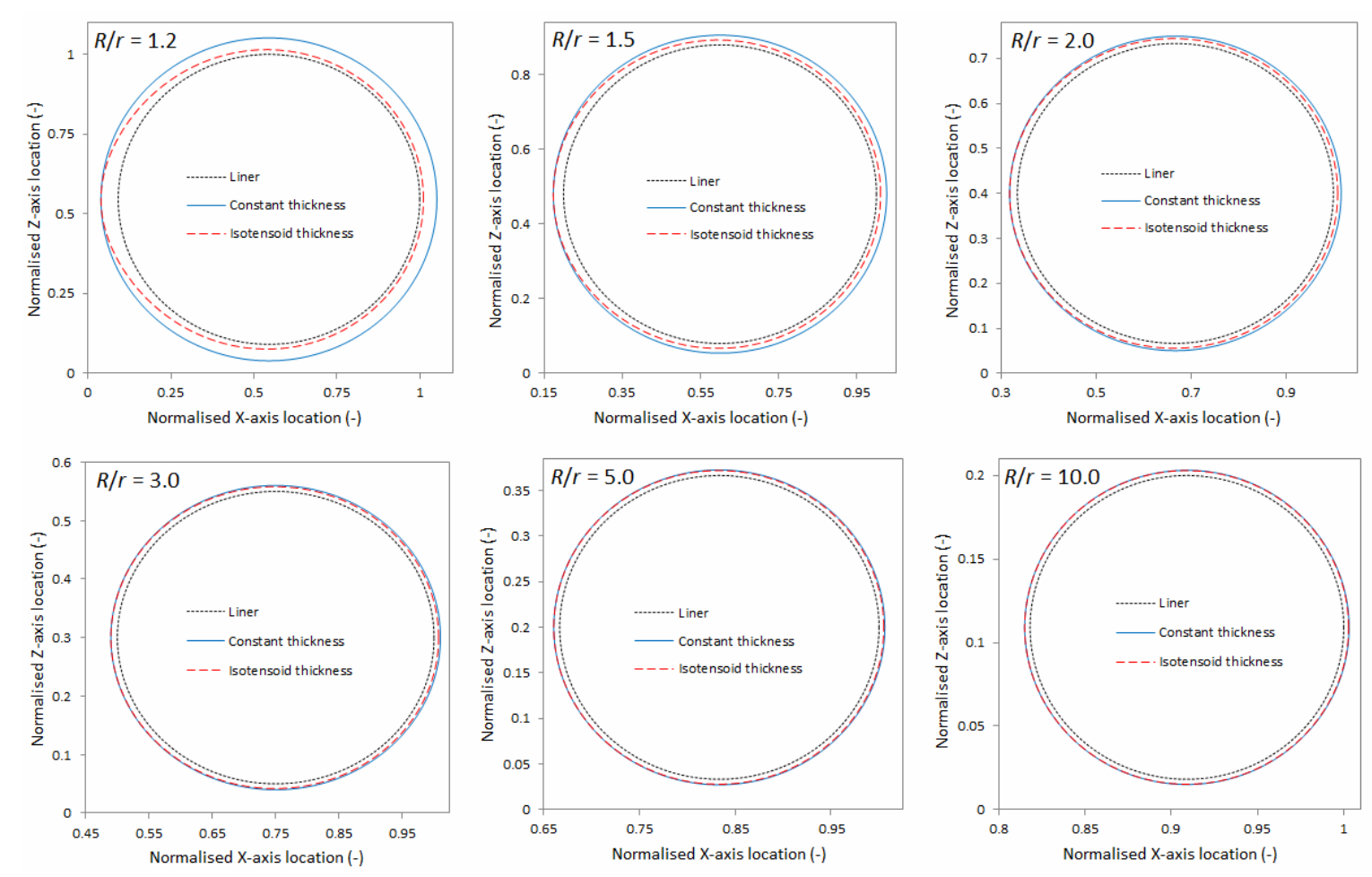

Figure 9: Circular and isotensoid thickness profiles of isotropic toroidal vessels of various radius ratios (distances normalised with respect to the largest cross-section dimensions $-R / r=1.2$ )

Through the analysis of Eqn. 3 it can be deduced that toroidal shells with circular cross-sections and constant wall thicknesses develop maximum hoop stresses at the inner equator of the structure $\left(\varphi=180^{\circ}\right)$ when they are subjected to internal pressure [18,31]. This has been proven in the literature when Blachut [51] and Adibi-Asl [40] observed that metallic toroidal shells formed "plastic hinges" around the inner equator of the structures when pressurised while large sections of the shell wall continued to deform elastically. Failure has also been found to occur at the inner equator of toroidal pressure vessels in several other studies [45, 52, 77]. The variance in hoop stress from the inner to the outer section of toroidal structures is caused by the differences in surface area and concave/convex curvature, which causes non-uniform deformation under internal pressure. Geuskens et al. [50] attempted to explain this phenomenon with reference to a diagram (similar to Figure 7Error! Reference source not found.) by stating that the close stacking of hoop-orientated circular lines around the inside compared to the outside caused the high meridional membrane stiffness on the inside of the pressurised torus. Because of this, the use of circular constant-thickness toroidal vessel configurations is not ideal as large areas of 
the shell will be thicker than what is required. This problem can be avoided by increasing $R / r$ - large enough values will cause toroidal vessels to approach circular cylindrical shell (a hoop-to-axial stress ratio of 2:1) [41]. Unfortunately, doing this does compromise the volumetric efficiency and space-saving potential by increasing the central hole size. It is clear that circular, constant-thickness toroidal vessels are to be avoided if vessel efficiency is to be maximised. In order to achieve this, several techniques are possible: (1) maintain constant wall thickness and change the cross-sectional geometry [33], (2) change both the wall thickness and the crosssectional geometry [33], (3) maintain circular cross-sectional profiles but vary the wall thickness where required $[34,90]$ or (4) optimise fibre winding angles and subsequent patterns of toroidal CPVs to create isotensoid designs [91]. The following sections will address several of these possibilities.

Other innovative design methods have also been proposed more recently to increase the structural integrity of isotropic toroidal pressure vessels. Internal strut-like bracing components were numerically analysed by $\mathrm{Vu}$ [92] who found that vertically-orientated braces located close to the inner equator provided significant strength increases compared to ordinary circular toroids. No information was given regarding possible manufacturing methods or vessel-strut joining techniques which are important to avoid local failure locations. The addition of stiffened ribs to the outside of toroidal shells to increase external buckling performance has also been addressed $[48,49]$ however this sort of technique is not suitable for toroidal CPVs for on-board gaseous fuel storage applications.

\subsection{Optimisation of cross-sectional geometry}

If constant-thickness walls are to be used in the design of toroidal pressure vessels then non-circular crosssectional geometry is necessary. In an early study, Steele [93] considered the volumetric and mass efficiencies of circular, elliptical, modified elliptic and equal stress-shaped isotropic toroidal pressure vessels and concluded that, for practical purposes, the torus with circular cross-section produced the minimum weight of the given examples for both constant and variable wall thicknesses. Any significant deviation from circular cross-sections was found to cause large decreases in structural performance that required excessive local wall thickening. The numerical study by $\mathrm{Vu}$ [33] using Differential Evolution and Particle Swarm Optimisation methods showed that among various cross-sectional shapes elliptical profiles resulted in the largest material savings, with circular cross-sections having thickness variation producing an optimal balance of weight saving and manufacturability. It should be noted that the results of both studies (as well as several studies in Section 3.3) were limited to and dictated entirely by the pre-selected cross-sectional shapes. True geometry optimisation should begin with a set of design criteria (i.e. maximum strength, minimum weight) and work towards an optimal solution with an essentially unlimited number of available geometry possibilities.

Work of this nature has since been undertaken in several studies [18, 94]. Zu et al. [18] used continuum theory (considers the role of the fibres and the matrix) and the optimality condition of equal shell strains to numerically determine optimal cross-sectional shapes of helically-wound $\left([ \pm \alpha]_{\mathrm{n}}\right)$ toroidal CPVs while taking shell thickness build-up around the cross-sectional profile into account. Optimal toroidal CPVs were lighter in weight and had lower and wider profiles than circular toroids of equal vessel volume. A comparison of circular and optimal profiles of a $R / r \approx 1.85$ toroidal vessel from the study can be seen in Figure 10a. The study also found that the optimal cross-sectional shape deviated further from a circle as $R / r$ decreased which further justifies the findings of Blachut [51] which were discussed in Section 4. The work provided important crosssectional shape optimisation information with regard to toroidal CPVs, which was however limited by constant wall thickness and geodesic winding assumptions. These shortcomings were addressed when $\mathrm{Zu}$ et al. [95] extended their previous work to combine isotensoid toroidal structures with friction-based non-geodesic winding patterns. Geodesic winding had previously been considered in the majority of filament wound CPV investigations and can be described as the shortest path between two arbitrary points on a continuous surface [96]. Geodesic paths are compatible with pure tension meaning that adjacent filaments will not slide against each other under CPV inflation [44]. Geodesic paths also show great stability on curved surfaces however they limit the available design space due to being entirely determined by the initial winding angle and underlying cross-sectional profile [95]. The optimal toroidal CPVs from the work (Figure 10b) produced lower stresses than their geodesic equivalents but this was thought to be due to the overall decrease in the winding angle and not the change in cross-sectional shape. 
(a)

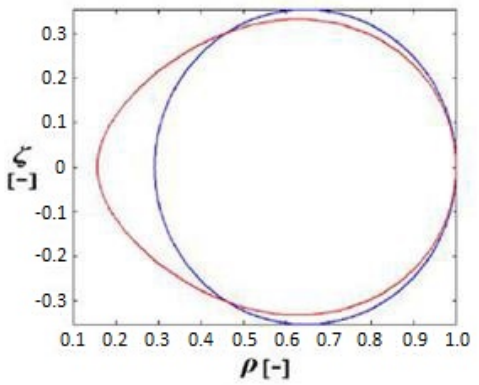

(b)

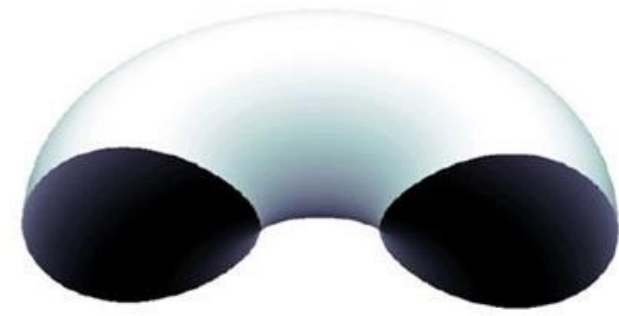

Figure 10: (a) Cross-sectional profiles of optimal (red) and circular (blue) toroidal vessels of equal volume [18]. $\rho$ and $\zeta$ are normalised geometrical parameters; (b) sectional view of an isotensoid, non-geodesically wound toroidal vessel obtained by Zu et al. [95]

\subsection{Optimisation of vessel shell thickness and the "natural thickening effect"}

It is clear that wall thickness variation is required to offset non-uniform hoop stresses if circular crosssectional profiles are to be used in the design of toroidal pressure vessels [40, 51, 90]. A more recent numerical study varied the shell thickness around the cross-section of circular steel toroids to create a constant von Mises stress distribution [34]. Optimal thickness distributions were almost perfectly uniform for larger radius ratios $(R / r=5)$ but became significantly non-uniform when $R / r=1.25$, providing significant weight reductions as well as contained-volume increases when compared to constant-thickness equivalents. Three radius ratios $(R / r=$ $1.25,2.5$ and 5$)$ were considered by fixing the centreline radius $(R=100 \mathrm{~mm})$ and then varying the crosssectional radius. It is important to note that both Kishida et al. [90] and $\mathrm{Vu}[33,34,92]$ took numerical approaches to their work. This is almost certainly due to difficulties and costs involved in manufacturing metallic toroidal vessels through hot rolling and spinning processes but more specifically due to accuracy and tolerance issues that exist between theoretical and actual shell thicknesses using these processes $[45,51]$. Tolerance issues of metallic shell thicknesses were also raised by Li and Cook [31] who only considered constant-thickness metallic liners in their study of Type III toroidal vessels for this practicality reason.

Toroidal CPVs are generally manufactured using a filament winding technique as described in Section 3.4. Due to differences in surface area between the inner and outer sections of a toroidal structure, the shell thickness around the central hole region builds up more than the outer shell section. This phenomenon is referred to as the natural thickening effect which has been discussed in various studies [8, 31, 53, 76, 81, 83]. If utilised effectively, the natural thickening effect could create a near-uniform hoop stress distribution around the crosssection of circular toroidal CPVs which would fully utilise the filament winding process and eliminate the need for additional manufacturing processes to offset non-uniform hoop stress. It is therefore surprising that such a promising technique has received little attention throughout the literature.

Recently, Kuznetsov and Nekhoroshikh [83] utilised a carbon/epoxy overwrap to reduce the mass of a toroidal vessel design by 45 percent compared to a Type I equivalent. Information about the winding procedure was lacking in the article however the final overwrap varied in thickness at a ratio of 10:1 from the inner to outer equators. This significant variation in overwrap thickness is almost certainly due to natural thickening caused by the toroidal vessel's significantly small radius ratio $(R / r \approx 1.2)$. The variation in overwrap thickness was in fact so severe that the vessel failed at the outer equator even though this location experiences the least hoop stress with constant-thickness circular profiles. It is highly likely that the influence of natural thickening was underestimated or neglected, therefore resulting in inadequate outer equator reinforcement. An earlier study [81] reported that the thickness variation caused by the winding of aramid fibres around an aluminium toroidal liner almost exactly accounted for the variation in hoop stress around the circular cross-section. Unfortunately, no geometric information was provided in the article so further analysis of the particular vessel design proves difficult. More recently, Vick and Gramoll [8] developed an analysis technique to optimise the fibre lay-up of orthotropic toroidal CPVs with circular cross-sections by producing equal stress distributions in each ply layer while accounting for the natural thickening effect from the fibre lay-up process. Four-layer unit-cell fibre layups of stacking sequence $[0 / \pm \alpha / 90]_{\mathrm{n}}$ were considered and an optimal angle-ply orientation of approximately $\alpha=$ 
$\pm 9^{\circ}$ (offset from the cross-sectional axis) was reached when the maximum fibre and transverse direction stresses in each shell layer were equalised. It should be noted that in reality it would be difficult to produce toroidal CPVs with $0^{\circ}$ and $90^{\circ}$ fibres as toroidal filament winding does not lend itself well to such winding angles unless some form of tape or fabric composite is utilised. There is then the risk of ply wrinkling and void formation with tape/fabric usage due to the complex double-curvature toroidal geometry.

The previously-mentioned studies have all been limited to singular toroidal radius ratios or have utilised fibre patterns which deviate from what is used in the majority of other toroidal CPV-related research. Li and Cook [31] developed a mathematical approach to optimise the design of Type III toroidal vessels using membrane shell theory which provided a more general solution for calculating natural thickening of toroidal CPVs - taking into account the natural thickening effect, fibre pre-tension, the load-bearing capacity of the composite overwrap and its interaction with the metallic liner. A Type III toroidal vessel $(R / r=2.17)$ optimised in [31] showed a $46 \%$ weight reduction compared to a monolithic metal toroidal vessel of uniform shell thickness. An equation to determine the thickness distribution around the toroidal cross-section with regards to natural thickening was also developed and used as part of the study. A modified version of this equation (to account for changes to the $\varphi=$ $0^{\circ}$ location - detailed in Section 3.1) is given by,

$$
t_{\phi}=\frac{\left(R+r^{2}\right) t_{A}}{R+r^{\prime} \cos \phi}
$$

The above equation makes it possible to calculate the thickness at any point around a circular cross-section $\left(t_{\varphi}\right)$ as long as the thickness of the composite overwrap at a specific reference point (i.e. the outer equator $\left.\left(t_{A}\right)\right)$ is known. Eqn. 6 is based on a simple relationship between the shell thickness required to maintain a specific operating pressure and the distance from the axis of revolution [31]. The relationship assumes that the product of the shell thickness and the distance to the axis of revolution of any point around the circular cross-section is equal to the product of these parameters at a known reference point. This assumes that the number of fibres passing through a cross-sectional slice of the torus at any cross-sectional location is constant. A brief analysis of Eqn. 6 shows that the difference in thickness between the inner and outer equators is geometrically dependent on $R / r$. This has also been previously noted by Blachut [76].

Until now, Eqn. 6 has only been used in conjunction with singular toroidal $R / r$ values $(R / r=2.17[31], R / r=$ 1.5 [8]) so there is still a need to study the influence of $R / r$ on the effectiveness of winding thickness profiles in offsetting hoop stress variation in circular toroidal CPVs. To address this issue, a brief theoretical analysis is presented. The analysis begins by determining the required shell thickness at a chosen reference point using Eqn. 5. This thickness is then used in Eqn. 6 to determine the thickness distribution for any value of $R / r$. For the purposes of this analysis, the outer equator (A) is used as the reference point as the hoop stress is at its maximum (winding-thickened profiles vary their thickness in such a way that the subsequent hoop stress variation is opposite to that of constant-thickness profiles). This is shown graphically in Figure 11a.

Toroidal vessels are assumed to have an isotropic material yield strength of $\sigma_{\text {yield }}=2459 \mathrm{MPa}$ (corresponds to $0^{\circ}$ tensile strength of unidirectional carbon fibre epoxy [97]) and a safety factor of 2, giving an allowable strength of $\sigma_{\text {allow }}=1230 \mathrm{MPa}$. The vessels are also required to maintain an internal pressure of $p=40 \mathrm{MPa}$, which is the maximum operating pressure allowed as part of ISO 11439:2013 [12]. The hoop stress variations (normalised with $\sigma_{\text {allow }}$ ) between the inner and outer equators of several winding-thickened toroidal vessels of various $R / r$ are calculated and are shown in Figure $11 \mathrm{~b}$. Winding-thickened profiles are unable to truly offset hoop stress variation for any value of $R / r$. Nevertheless, larger $R / r$ values produce greater uniformity. Normalised thickness profiles of winding-thickened and isotensoid toroids are then compared which further highlights that while both profiles share the same general shape, winding-thickened shells do not vary in thickness drastically enough between the toroidal equators to reach an isotensoid state (Figure 12). It is concluded that winding-thickened profiles (using Eqn. 6) cannot completely offset non-uniform hoop stresses of circular toroidal CPVs. This results in larger vessel masses compared to equivalent isotensoid profiles as well as the movement of the hoop stress maxima to the more-vulnerable outer equator (for accidental impact damage). However, Figure 13 shows that better stress uniformity is still achieved when compared to constant-thickness toroids, particularly at smaller $R / r$ values. It should be noted that $1.2<R / r<1.5$ toroids exceed thin shell criteria for approximately $140^{\circ}<\varphi<220^{\circ}$ (near their inner radius). 


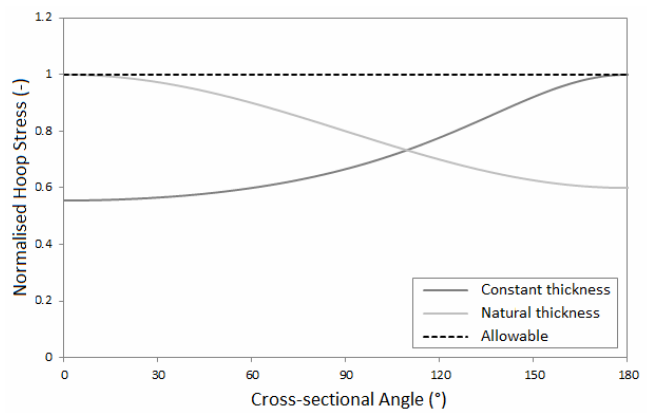

(a)

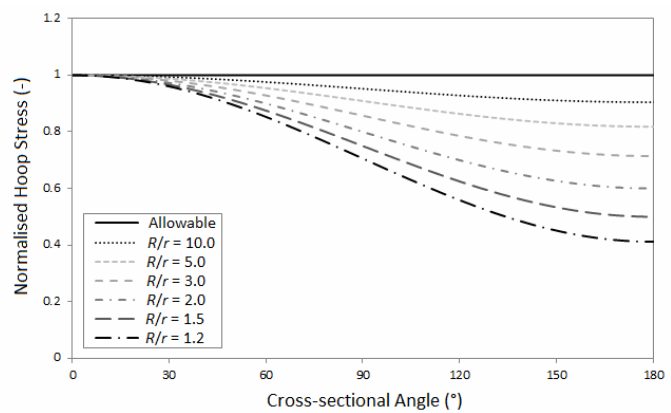

(b)

Figure 11: (a) Hoop stress variation (normalised with allowable stress) of constant and winding-thickened toroids of $R / r=2.0$; (b) hoop stress variation (normalised with allowable stress) around winding-thickened (from Eqn. 6) toroids of various $R / r$

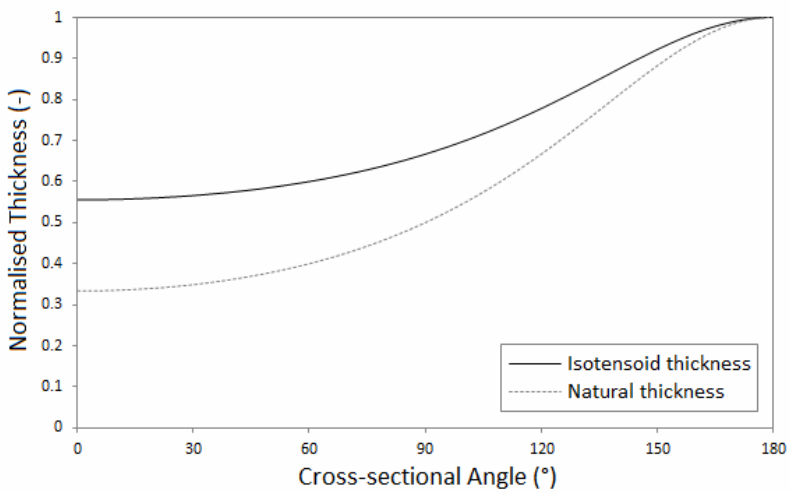

Figure 12: Shell thickness (normalised with max. thickness of particular profile) comparison between winding-thickened and isotensoid toroids of $R / r=2.0$
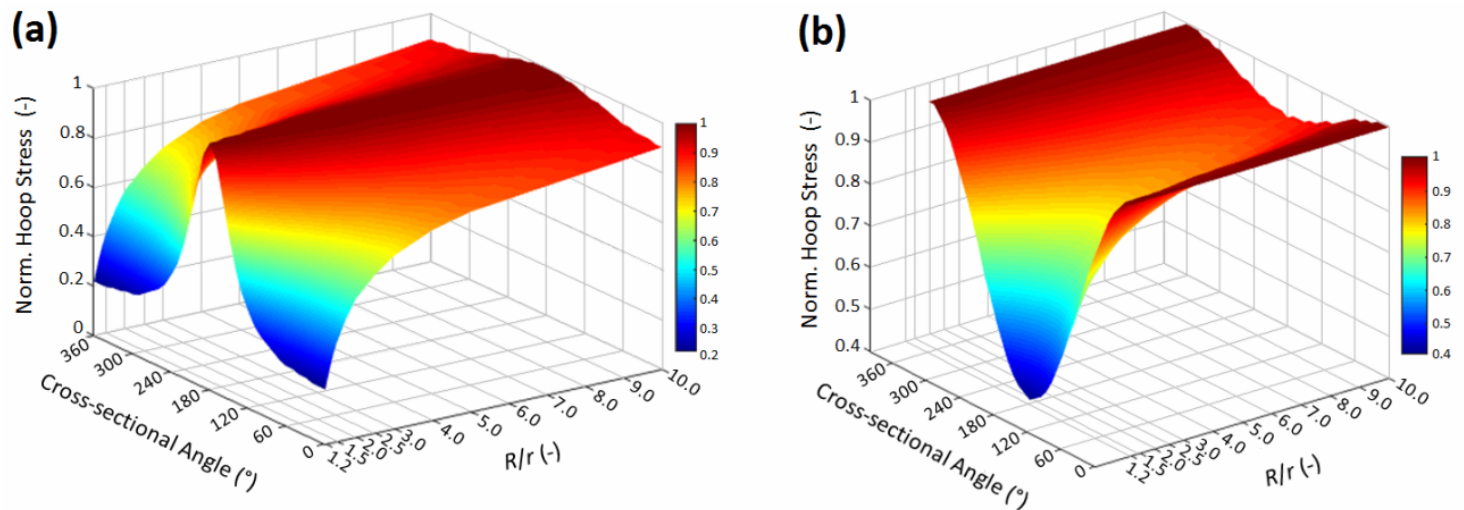

Figure 13: 3D surface plots showing the influence of $R / r$ on normalised hoop stress variation around circular toroidal cross-sections; (a) constant shell thickness, (b) natural winding thickness (using Eqn. 6)

Another equation to determine winding-thickened profiles of circular toroidal CPVs has been given in [35, $38,53,98]$ :

$$
t_{\phi}=\frac{(R+r) t_{A}}{R+r \cos \phi} \cdot \frac{\sin \alpha_{A}}{\sin \alpha}
$$


where $\alpha_{A}$ is the initial winding angle and $\alpha$ is defined in Figure 4 .

This equation differs from Eqn. 6 in that it accounts for the change in helical winding angle about the crosssectional profile. Its use is accompanied by two assumptions: (1) the fibre volume fraction is maintained consistently around the toroidal structure and (2) the number of filaments in a cross-section is always constant. Eqn. 7 provides great flexibility as it can be used to calculate thickness distributions of toroidal CPVs in which the fibre angle varies as it travels around the structure as opposed to angle-ply winding patterns where the winding angle is fixed. The advantages of this are discussed in greater detail in Section 4.3. If used in the analysis of angle-ply toroidal CPVs, Eqn. 7 simply reverts back to Eqn. 6. While Eqn. 7 provides greater design flexibility than Eqn. 6, an analysis of $R / r$ effects on its use is not performed here due to the added complexities associated with the accompanying geodesic winding formulae. It is recommended that such an analysis be performed as a separate work.

\subsection{Optimisation of winding angles}

It is widely known that the use of composite materials is an effective way of reducing the mass of structural components while maintaining or even increasing their strength. It is also known that this comes at the cost of increased design complexity due to the difference in properties between fibres and matrices as well as the almost unlimited number of lay-up combinations that are possible. It is for this reason that determining optimal winding trajectories is one of the most crucial design issues facing the development of toroidal CPVs. Early studies into the optimisation of toroidal CPVs only considered winding paths based on geodesic trajectories (explained in Section 4.1). The geodesic curvature of a torus $\left(k_{g}\right)$ can be given by Liouville formulae [99]:

$$
k_{g}=\frac{d \alpha}{d l}+\frac{\sin \phi}{R+r \cos \phi} \cos \alpha
$$

where $l$ denotes the coordinate along the fibre direction. Other parameters have already been defined in Figure 3 and Figure 4.

Such studies began when Marketos [44] observed that circular cross-sections did not provide structurally optimal solutions for geodesically-wound toroidal CPVs. Circular cross-sections were also said to not lend themselves to the filament winding process because the hoop-to-axial stress ratio around the toroidal crosssection varied in a way that was incompatible with the rate of change of the filament winding angle. However, Marketos' finding was somewhat contradicted by the numerical example presented at the end of the article which showed that a very-near circular torus could be successfully filament-wound with a geodesic-based helical trajectory if the initial winding angle was set to $42^{\circ}$ and began at the inner equator of the toroidal shell. In more recent times, the use of friction-based non-geodesic winding has been studied to further increase the performance and design flexibility of toroidal CPVs. Non-geodesic winding takes advantage of the friction between the tensioned fibres and the toroidal mandrel to allow the fibres to deviate from geodesic angles and thus provide a more uniform stress distribution however it must be implemented carefully and comply with the available slippage coefficient $(\lambda)$ between the fibres and mandrel to avoid slipping from the pre-selected trajectory. $\mathrm{Zu}$ et al. [53] determined optimal non-geodesic fibre trajectories and laminate thickness distributions for toroidal CPVs with circular cross-sections. A comparison of geodesic and non-geodesic winding paths can be seen in Figure 14(a-b) where non-geodesic trajectories centralised between $\pm 50^{\circ}$ to $\pm 56^{\circ}$ to satisfy strength, non-slip and non-bridging criteria of the graphite/epoxy vessel. It should be noted that the range of non-geodesic trajectories were almost identical to optimal helical winding angles obtained for cylindrical CPVs in various studies [100-102] and were found to maximise the utilisation of laminate strength and minimise the weight of the circular toroidal vessel compared to geodesic trajectories (Figure 14c). Unfortunately, the range of $R / r$ values analysed in the work was limited to $3 \leq R / r \leq 6$. To fully utilise the volumetric potential of toroidal CPVs, smaller radius ratios of approximately $1.25<R / r<3$ should also be studied. 


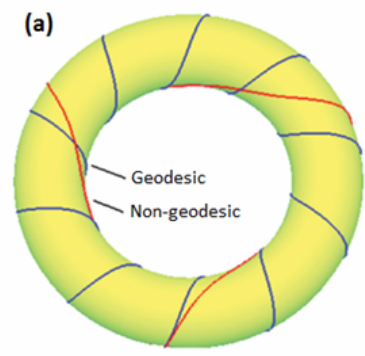

$\lambda=0.2$
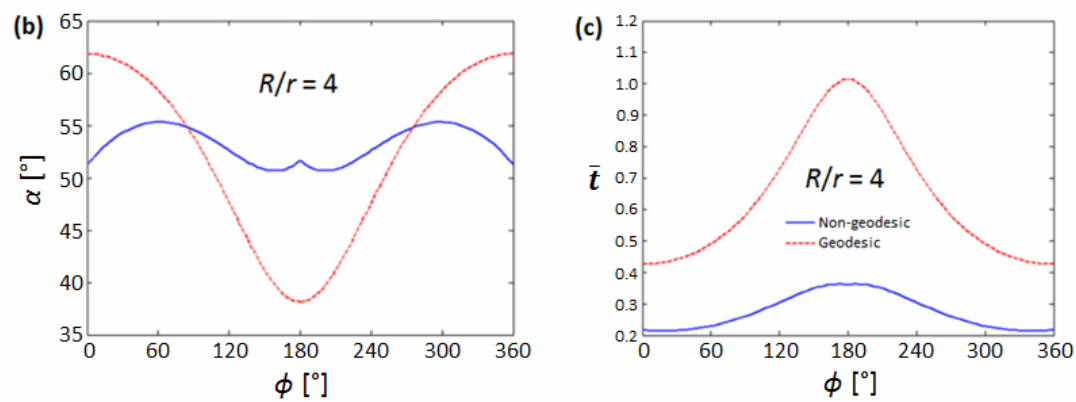

Figure 14: Numerical comparisons of geodesic and non-geodesic winding angles from Zu et al. [53]; (a) winding paths for a slippage coefficient of 0.2 ; (b) winding angle developments for a toroidal vessel of $R / r=4$; (c) shell thickness distributions for a toroidal vessel of $R / r$ $=4$

(a)

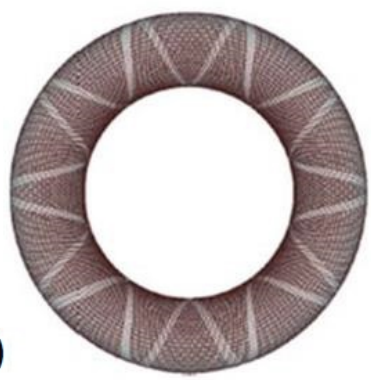

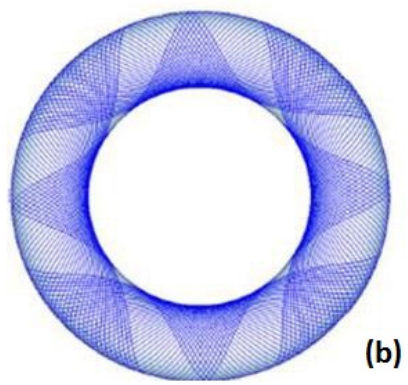

(b)

Figure 15: Optimal symmetrically helical (a) geodesic trajectories after 300 wound circuits of mandrel; (b) non-geodesic trajectories after 160 wound circuits of mandrel [36]

$\mathrm{Zu}$ et al. [38] further advanced their studies by considering variable slippage coefficients in the analysis of optimal non-geodesic toroidal helical-and-hoop winding. Optimal non-geodesic fibre trajectories varied from $51.48^{\circ}$ at the outer equator to $55.12^{\circ}$ at the inner equator while maximum fibre slippage tendency was found to occur on the concave surfaces around the inner section of the circular toroidal mandrel. Non-geodesic winding patterns also benefit toroidal cross-sections that deviate from circular profiles. The "eye" shaped toroidal CPV shown earlier in Figure 10b resulted in an optimal winding path that varied from $5^{\circ}$ at the outer equator to approximately $50^{\circ}$ at the inner equator [95]. Increasing the slippage coefficient $(\lambda)$ increased the structural performance of the toroidal CPV by lowering the possible overall winding angle - resulting in shorter total fibre length and less material usage. This work was then extended to include full-coverage criteria in conjunction with existing structural requirements [36]. Like previous studies, non-geodesic winding trajectories provided better structural efficiency than geodesic equivalents (Figure 15) by providing a more-uniform fibre coverage around the entire mandrel. To advance the development of toroidal winding optimisation, the effect of openings (i.e. inlet/outlet valves) on the winding patterns and structural optimisation of toroidal CPVs was proposed. This would have a significant influence on optimal winding patterns due to the introduced obstruction and associated stress concentration created by the opening.

In a related study, $\mathrm{Zu}$ [37] compared single-helical and hoop-and-helical winding techniques on toroidal CPVs and found that single-helical winding provided better stability for both non-slippage and non-bridging criteria. In particular, it was reported that toroidal CPVs with $R / r<3$ and hoop-to-helical layer thickness ratios over 1.5 should avoid the use of netting-based, non-geodesic fibre trajectories because high coefficients of friction are required but difficult to achieve in practice. As stated earlier in this section, small radius ratios of 1.2 $<R / r<3$ should be selected to fully realise the volumetric efficiency and space-saving potential of toroidal CPVs so geodesic or semi-geodesic paths should be employed in these cases. In fact, it is desirable to avoid non-geodesic winding altogether unless the friction between the toroidal mandrel and wound fibres can be accurately controlled. Any fibre slippage may lead to weak areas that would be prone to premature vessel failure. 
After a review of the toroidal CPV-related literature, it is clear that the majority of studies have focussed on $[ \pm \alpha]_{\mathrm{n}}$ helical/angle-ply fibre patterns with $[0 / \pm \alpha]_{\mathrm{n}}$ hoop-and-helical patterns used in some instances as well. This is due to design criteria which require a high thickness percentage of helical layers compared to hoop-orientated layers to ensure no fragmentation occurs during burst failure [103]. For this reason, the following sections will continue to focus on these fibre patterns. It is important to understand the damage mechanisms and failure modes of these stacking sequences at both coupon and full vessel levels in order to effectively design damage tolerant toroidal $\mathrm{CPV}$ s for mass production and commercial usage that comply with safety standards.

\section{Damage tolerance of composite pressure vessels}

Fibre-reinforced polymers are susceptible to damage induced by low-velocity impact due to accidental drops, falling hand tools and other incidents in the service life of products [104]. These can affect their mechanical performance and reduce their structural integrity. Replacing toroidal CPVs that have suffered minor damage may be excessively expensive and un-necessary. Vessels should instead be able to continue to operate with minor levels of damage so long as that damage can be quantified and assured to be within safe operating levels. Currently it is common procedure to either ensure composite overwraps are slightly thicker than minimum strength requirements or to have a sacrificial material as the outer vessel shell layer to accommodate minor levels of damage. These design methods are quite conservative due to the lack of analysis tools, thus adding potential un-necessary mass that lowers the overall pressure vessel efficiency. The following section highlights the possible causes of vessel over-design that would occur by following requirements of current state-of-the-art CPV design standards. Three design qualification tests are vital to damage tolerant CPV design and will be highlighted to cover various damage types that should be accounted for when optimising toroidal vessel winding patterns. These tests have been specifically designed to accommodate cylindrical CPVs so proposed changes are discussed that would apply to toroidal vessels.

\subsection{Composite pressure vessel standards}

A number of international standards for the design, certification and on-going inspection of high pressure gaseous storage vessels are in existence that all apply to conventional cylindrical geometries $[12,84,85,105$ 108]. Over the past decade, toroidal vessel technology has received significant interest however there are no specific standards currently relating to their design and certification. The lack of specific design qualification criteria is likely to lead to the over-designing of toroidal CPVs which would ultimately result in excessive vessel mass and lower vessel efficiency than what is possible. Until such time that specific standards are developed, toroidal CPV designs need to adhere to the strictest international standards for cylindrical CPVs, such as ISO 11439 [12] and ANSI/CSA NGV2 [85]. These standards specify minimum requirements for cylindrical vessel performances by specifying service conditions, service life spans, maximum operating pressures, design qualification tests and non-destructive testing and inspection methods. Vessel designs must also have fatigue endurance that exceeds their specified service lives and most importantly - they must fail by leak-before-burst [109] when pressure cycled to failure after an appropriate number of pressure cycles.

These codes and standards outline a sufficient number of requirements to ensure all vessel designs that meet the criteria will operate safely throughout their service life. However, a lot of design specifications are left to the manufacturer which can easily lead to over-designing of wall thicknesses to ensure all qualification tests are successfully completed. For example, ISO 11439:2013 [12] does not provide any design formulae or list permissible stresses or strains for Type III and IV vessels. It only requires that vessel designs be established through appropriate calculations and the passing of all materials, design qualification, production and batch tests listed in the standard. A full re-design is necessary if a vessel fails any one of these tests. As a result there is a strong likelihood of vessel over-design given the high costs and time involved in producing an updated design and a new batch of prototypes to submit to testing. Three significant damage tolerance-related design qualification tests will now be summarised to highlight the vagueness of the given requirements and to discuss how they could be adapted to toroidal vessel geometries.

\subsubsection{Drop test (impact from free-fall)}

A drop test (Figure 16) is specified as a design qualification test in several leading CPV design standards [12, 85] to ensure a CPV will either continue to safely contain its gas or fail via leak-before-burst after being dropped 
from a low height. The standards that specify this test were written with cylindrical vessels in mind so the requirements and language relate to such.

Three cylinders are required for three separate drop tests. Each is dropped from a different position $(1-$ horizontally, 2 - vertically onto each dome and 3 - at $45^{\circ}$ onto one dome) at ambient temperature and without internal pressurisation onto a smooth, horizontal concrete floor from $1.8 \mathrm{~m}$ above. More specific information can be found in $[12,85]$. The impacted cylinders are then pressure cycled between $2 \mathrm{MPa}$ and 1.3 times their operating pressure at ambient temperature for 1,000 times per year of their specified design lifetime. No failure (leak or rupture) may be observed within the initial 3,000 cycles. Failure by leakage is then acceptable over the remaining pressure cycles. Burst failure is not acceptable at any stage during the full amount of cycles.

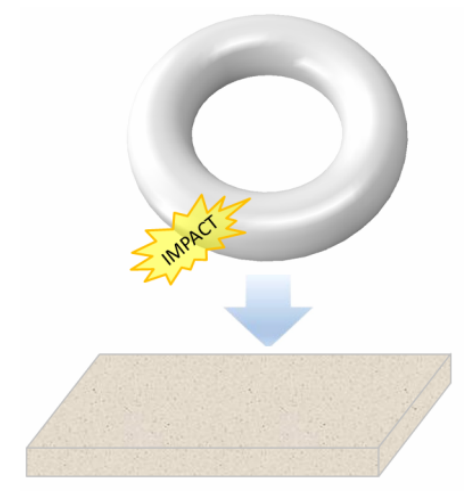

Figure 16: Free-fall (drop) impact test scenario (adapted from [110])

Drop testing of toroidal CPVs would have some obvious differences in methodology compared to cylindrical vessels. As stated above, three cylindrical vessels are required for drop tests to account for both cylinder and dome sections. An advantage of toroidal vessels is that they do not have domed heads so two of the three test scenarios do not apply. For toroidal vessels with circular cross-sectional profiles and constant wall thicknesses, the lowest hoop stress occurs at the outer equator ( $\mathbf{A}$ in Figure 3 ) and the highest hoop stress location that is susceptible to such dropping scenarios occurs at the poles (B in Figure 3). If the design utilises a variable wall thickness then this does not necessarily apply. However, it is safe to assume that locations $\mathbf{A}$ and $\mathbf{B}$ will be the maxima and minima hoop stress locations (in either order) so there is no need to test any other point between these two locations. Based on these assumptions, it would be logical to conduct two drop tests for a circular toroidal CPV design: (1) one vessel dropped from $1.8 \mathrm{~m}$ so that a pole (B) of the cross-section contacts the impact surface and (2) one vessel dropped onto its outer equator (A) from a height where the vessel's centre of gravity is $1.8 \mathrm{~m}$ above the impact surface. A third drop test could be conducted if the inlet/outlet valve is located at a different point which is vulnerable to such an impact. An additional test should also be included that requires non-circular toroidal CPVs to be dropped onto the cross-sectional location that has the highest curvature if that location does not occur at $\mathbf{A}$ or $\mathbf{B}$. High curvature locations are likely to have local stress concentrations which could be critical damage locations. The location of such cross-sectional points would have to be theoretically proven prior to testing.

\subsubsection{Composite flaw tolerance test}

On-board gaseous storage vessels are not removed from vehicles for periodic hydraulic tests and inspections. For this reason, a composite flaw tolerance (CFT) test is performed to ensure that any defect present in CPV walls that could potentially lower safe operating pressures or reduce the vessel service life will be detected by non-destructive inspection techniques. Two minimum defect sizes are specified in both ISO 11439 [12] and ANSI/CSA NGV2 [85]: (1) a short, deep cut (25 mm long, $1.25 \mathrm{~mm}$ deep) and (2) a longer, shallower cut (200 $\mathrm{mm}$ long, $0.75 \mathrm{~mm}$ deep). Reasoning behind the choice of flaw sizes is not given in either standard, however experiments from the literature have concluded that increased flaw depth causes decreased burst pressure [111] and flaw lengths and flaw depths need to exceed certain thresholds to cause any decrease in CPV fatigue life [24]. These thresholds will vary between CPV designs due to the large number of design variables. 
Both cuts are made in the longitudinal direction at mid-cylinder. Transverse and longitudinal flaws have previously been experimentally compared [111] with CPV failure only occurring at the latter due to the cutting of structurally-important hoop-layer fibres. The width and tip radius of cuts are not specified in the standards however it is assumed that they are very thin compared to their length. Flaw widths of $1.0 \mathrm{~mm}$ [111] and 2.0 $\mathrm{mm}$ [24] have been used in separate studies related to flaw testing of cylindrical CPVs so this range is considered acceptable. A method of creating the cuts is not specified, although after a review of the literature it seems that the use of slot drill piece (Figure 17a) is most common. Both standards agree on all CFT test methods, with ISO 11439 specifying that cuts are to be made on fully completed vessels (complete with any protective coatings) while ANSI/CSA NGV2 specifying the use of uncoated cylinders. ISO methodology takes a "real world" representation of damage that may occur during a CPV's service life while ANSI/CSA opt for a "worst case scenario" as the cuts will penetrate more of the structural composite shell. Flawed cylinders are then subjected to pressure cycling and failure analysis regimes identical to those of drop tests (Section 5.1.1).

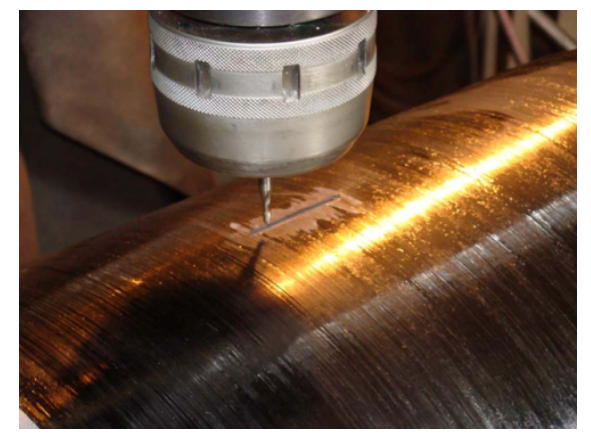

Figure 17: Drilling procedure used to form a slot notch in the cylindrical section of a CPV [24]

The methodology of CFT tests would have to be significantly altered for the design of toroidal CPVs. Current methods require flaws to be made in the longitudinal direction of cylindrical vessel sections in order to cut through structurally-important, hoop-directed fibres and provide a "worst case" scenario. These flaws are also made at mid-cylinder to avoid possible nearby stress concentrations from domed regions that could affect the initiation or propagation of composite damage. The flaw location with respect to the vessel cross-section is not specified due to the uniform hoop stress distribution that exists in cylindrical vessels with circular cross-sections and constant wall thicknesses. This would not be the case for toroidal CPVs as there would be non-uniform hoop stress distributions (for circular, constant shell thicknesses), non-circular geometries or non-uniform shell thickness distributions. It is therefore proposed that a single flaw be machined into the composite shell of a toroidal CPV at a location around the vessel's cross-section that is known to be the hoop stress maxima. It should be noted that difficulties in machining the flaw may arise if the maximum hoop stress location occurs at or near the inner equator of the vessel.

\subsubsection{Bullet penetration test}

The bullet penetration test is used to ensure that pressurised storage tanks do not burst and fragment if penetrated by high-energy projectiles while at working pressures. A cylinder is first pressurised to operating pressure (200 bar \pm 10 bar) with a compressed gas before being penetrated by a $7.62 \mathrm{~mm}$ diameter armourpiercing bullet $[12,85]$. The bullet must make contact with the cylinder sidewall at approximately $45^{\circ}$ and is required to completely penetrate at least one of the cylinder sidewalls (Figure 18a). The pressurised vessel must not rupture or burst upon penetration.

Hoop stress is typically uniform around the cross-section of cylindrical CPVs so only one bullet penetration test is required and the exact location of penetration on the vessel is not overly important. Unfortunately, hoop stress is likely to vary around toroidal CPV cross-sections unless offset through shell thickness variations or changes to cross-sectional geometry. Therefore, the penetration locations on toroidal CPVs have to be defined more specifically. If a cross-sectional geometry/shell thickness combination is used that produces a variable hoop stress distribution it seems logical that the location of highest hoop stress should be penetrated. This should be possible even at the inner equator if necessary. Alternatively, penetration should be located at the point of lowest composite shell thickness if the toroidal CPV design achieves a uniform hoop stress distribution. 


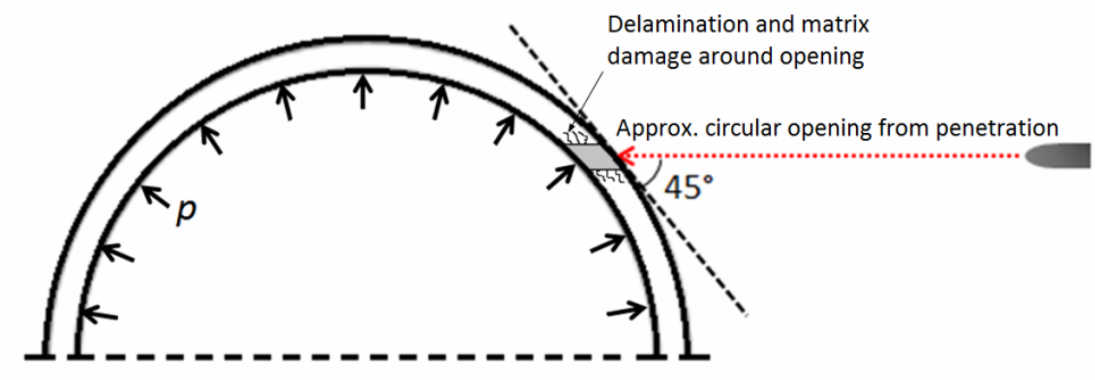

Figure 18: Bullet penetration of a cylindrical CPV

\subsection{Building block approach to design for design qualification tests}

Various steps need to be taken during the design and development of a toroidal CPV to ensure time, costs and resources are kept to a minimum. It would be extremely costly to use full-scale vessel tests early on in the design process so representative coupon testing through a building-block experimental approach [112] is an important step towards cost-effective development. The use of biaxially-loaded, coupon-based experiments would provide ample opportunity to analyse damage and failure behaviour of candidate winding patterns whilst allowing significant fibre angle and composite shell thickness optimisation to be achieved under various loading and damage scenarios. Varying the biaxial load ratio allows the determination of impact and notch-related failure behaviour at various points around a theoretical toroidal cross-section where hoop stress is likely to vary, thus varying the hoop-to-axial biaxial stress ratio. Varying the magnitude of biaxial loads allows the observation of impact and notch-related damage behaviour at various levels of pressurisation which would occur as the gaseous fuel tank empties during a single-fill cycle.

There is far less published work on the biaxial tensile loading of composite materials compared to uniaxial loading due to complexities associated with required specimen geometries and testing machinery. There are two generally accepted ways to introduce biaxial loads to composite specimens: a combination of internal pressure and axial loading of filament-wound tubular specimens or biaxial loads applied to the arms of flat, cruciform specimens [113]. Tubular specimens are advantageous as they do not suffer from edge effects that can be present in flat cruciform specimens; however problems can arise due to end effects (failure at tube ends due to clamping) and the influence of hydraulic oil which is used to generate internal pressure. Flat cruciform specimens provide an easier experimental approach so long as the cruciform is designed to promote acceptable failure in the central gauge region and not the loading arms which are only subjected to uniaxial loads [114116]. Despite such different approaches, both methods can give comparable results [117].

The use of a building block approach [112] is possible when designing a toroidal CPV for any damage tolerance-related design qualification test outlined in $[12,85]$. This can be achieved through the use of composite specimens with representative fibre patterns that would be subjected to:

- Drop-weight impact tests [118] to simulate the un-pressurised state of CPVs during drop tests.

- Centre-notch tensile tests to simulate CFT test requirements.

- Pre-strained, high velocity impact tests to imitate bullet penetration events of pressurised CPVs.

There are several assumptions that must be made and issues to be addressed for these building block approaches to become viable cost-saving design measures. The primary issue with impact related tests is ensuring that composite specimen sizes are large enough so that edge effects do not influence the shape and size of the impact damage. This has been achieved in previous studies by using composite panels with significantly large widths which were typically trimmed after impact and damage analysis to smaller widths prior to postimpact testing [119-121]. Back face splitting caused by bending effects may also occur if composite specimens are sufficiently thin which does not generally occur in CPVs due to shell curvature [122], internal pressure and the vessel liner which all aid in stiffer behaviour. Building block specimens can be made stiffer by increasing 
specimen curvature, increasing laminate thickness or utilising metallic back plates to simulate vessel liners. Once impact damage is assessed, specimens would then be subjected to tension-after-impact tests to simulate the required post-impact pressure cycling. Static tensile tests could simulate residual burst strength however fatigue tests are required to properly simulate drop testing requirements [12].

Centre-notched composite coupons have previously been studied under a variety of loading scenarios with various stacking sequences, fibre angles and notch lengths $(6.35 \mathrm{~mm}, 12.7 \mathrm{~mm}$ and $25.4 \mathrm{~mm})$ [123, 124]. Similar coupon specimens (Figure 17b) could be used to represent CFT scenarios even though notches/flaws have tended to be full-thickness in these studies. The use of full-thickness flaws is actually a useful simplification to make when using coupon-based testing as vessels must fail at the flaw location via leak-beforeburst according to CFT criteria [12]. It can therefore be assumed that a crack exists in the composite shell under the partial-depth CFT flaw which allows leakage to occur. Consequently, a partial-depth flaw is essentially equivalent to a full-thickness flaw when determining the maximum safe pressure.

In general, the majority of pre-strained impact testing of composites has previously involved uniaxial tensile pre-strains with low velocity impact events (i.e. $[125,126])$, with few studies on high velocity impacts [127129]. Unlike the other mentioned studies, penetration of tensile pre-loaded composite plates was achieved by Johnson et al. [128] who used $12 \mathrm{~mm}$ steel cube projectiles at approximately $100 \mathrm{~m} / \mathrm{s}$. Impactor size was the primary influence on damage size and residual strength while delamination damage was of only secondary importance. This would be different if penetration was not observed when using lower impact energies.

Biaxial tensile testing of representative specimens with angle-ply/helical lay-ups is likely to provide valuable insights into CPV damage and behaviour however there is currently very little on this in the literature, thus representing a significant gap in CPV-related research.

\subsection{Analysis-based certification of composite pressure vessels}

There is a need for analysis-based certification to supplement the conventional building-block experimental approaches [112] employed in aerospace engineering. In this regard, it is important to develop validated computational techniques to predict vessel strengths and failure modes, thus reducing the significant cost burden of experimental tests. Several different approaches with various levels of modelling complexity have been conducted in the literature to address this $[110,130-137]$. These include utilising $\left[ \pm \alpha_{\mathrm{n}}\right]_{\mathrm{s}}$ filament-wound coupons to characterise material properties and damage modes to predict burst failure $[131,132,138]$ and impact induced damage [110] in CPVs and subsequently propose optimised tank designs [133], developing composite damage laws for fibre property dispersion [134] and thermo-mechanical effects on burst failure [135], accounting for wound composite architecture [133]. The above studies consider combinations of fibre fracture and property dispersion, permanent shear strain, matrix micro-cracking and delamination along with liner and metal boss plasticity by using standard composite damage laws (i.e. Hashin, Hashin-Rotem, Puck) alongside extensive customisation via user subroutines and material characterisation testing. Further development and use of these numerical techniques is needed to optimise vessel geometries and fibre patterns as opposed to studying individual, pre-selected vessel configurations.

\section{Conclusions}

Toroidal composite pressure vessel development has matured substantially in recent times however there still exist many areas of further innovation. The work performed in this paper has given a comprehensive review of all current literature relating to toroidal CPV optimisation. This critical literature analysis has allowed key research gaps to be identified. It is clear that further research is needed to understand how to better utilise design and manufacturing approaches to offset non-uniform hoop stresses while considering the influence of discontinuities such as composite damage and valve placement on toroidal CPVs. Several original analyses have been carried out to complement work reported in the literature including an analytical study of $R / r$ on toroidal vessel thickness profiles. A focus on smaller radius ratios $(1.25<R / r<3)$ is required to maximise the potential space-saving and volumetric efficiency of the torus. Leading international CPV standards were analysed in order to adapt design qualification test requirements from cylinders to toroids. Building block approaches have been presented to aid the damage tolerant design of toroidal CPVs for the relevant design qualification tests. 


\section{Acknowledgements}

This original research was proudly supported by RMIT University and the Commonwealth of Australia, through the AA2020CRC.

\section{Appendix: Quick Reference Guide for Peer-reviewed Toroidal-related Literature}

A quick reference guide has been created to aid in toroidal CPV literature sourcing and is inspired by work presented in [63]. While there are some overlaps with [63], the majority of references and associated topics presented in this review have been published since then and have not been reviewed and collated in a single article until now.

\begin{tabular}{|c|c|c|c|c|c|c|c|c|c|c|c|c|c|c|c|c|}
\hline & & \multicolumn{3}{|c|}{ Material Type } & \multicolumn{3}{|c|}{$\begin{array}{l}\text { Method of } \\
\text { Study }\end{array}$} & \multicolumn{4}{|c|}{ Focus of Study } & \multicolumn{5}{|c|}{$\begin{array}{l}\text { Design Optimisation } \\
\text { Focus }\end{array}$} \\
\hline Author & Year & 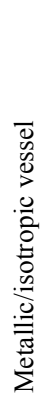 & 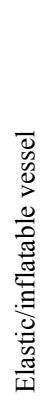 & 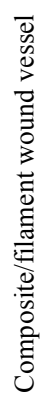 & 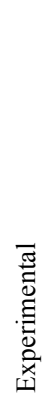 & 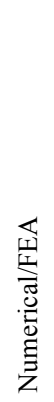 & 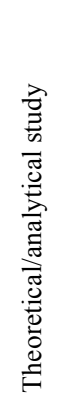 & 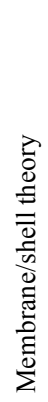 & 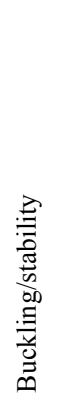 & 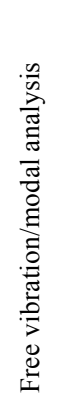 & 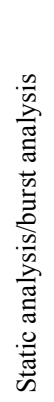 & 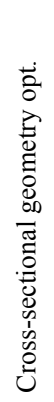 & 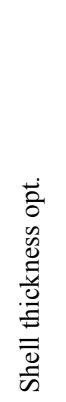 & 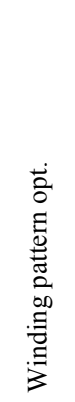 & 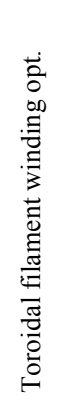 & 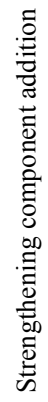 \\
\hline Adibi-Asl [40] & 2008 & $x$ & & & & $x$ & $x$ & & & & $x$ & & & & & \\
\hline Blachut [86] & 2003 & $x$ & & & $x$ & $x$ & & & $x$ & & & & & & & \\
\hline Blachut [76] & 2004 & & & $x$ & & $x$ & $x$ & & $x$ & & & $x$ & $x$ & & & \\
\hline Blachut [51] & 2005 & $x$ & & & $x$ & & $x$ & & & & $x$ & & $x$ & & & \\
\hline Blachut and Jaiswal [75] & 2000 & $x$ & & & & $X$ & & & $x$ & & & $x$ & & & & \\
\hline Colbourne and Flügge [42] & 1967 & & & & & & $x$ & $x$ & & & & & & & & \\
\hline Cook et al. [81] & 1998 & & & $x$ & $\mathrm{X}$ & & $x$ & & & & & & $x$ & & $\mathrm{X}$ & \\
\hline Du et al. [48] & $2015 \mathrm{a}$ & $x$ & & & $\mathrm{x}$ & $x$ & & & $x$ & & & & & & & $x$ \\
\hline Du et al. [49] & $2015 b$ & $x$ & & & $x$ & $x$ & $x$ & & & & $x$ & & & & & $x$ \\
\hline Galletly [74] & 1998 & $x$ & & & & $x$ & & & $x$ & & & $x$ & & & & \\
\hline Geuskens et al. [50] & 2013 & & & $x$ & & & $x$ & $x$ & & & $x$ & & & & & \\
\hline Hu et al. [35] & 2015 & & & $x$ & $x$ & $x$ & $x$ & & & & $x$ & & $x$ & $x$ & & \\
\hline Jiang and Redekop [66] & 2002 & $x$ & & & & $x$ & & & & $x$ & & & & & & \\
\hline Jiang and Redekop [67] & 2003 & $x$ & & $x$ & & $x$ & & & & $x$ & $x$ & & $x$ & & & \\
\hline Jones et al. [77] & 1999 & $x$ & & & $X$ & $x$ & & & & & $x$ & & & & & \\
\hline Jordan [55] & 1962 & & & & & & $x$ & $x$ & & & & & & & & \\
\hline Kishida et al. [90] & 1989 & $x$ & & & & $x$ & & $x$ & & & $x$ & & $x$ & & & \\
\hline Kisioglu [45] & 2011 & $x$ & & & $x$ & $x$ & & & & & $x$ & & & & & \\
\hline $\begin{array}{l}\text { Kuznetsov and Nekhoroshikh } \\
\text { [83] }\end{array}$ & 2015 & $x$ & & $x$ & $x$ & & & & & & $x$ & & & & & \\
\hline Kydoniefs [56] & 1967 & & $x$ & & & & $x$ & & & & $x$ & & & & & \\
\hline Kydoniefs and Spencer [57] & 1967 & & $x$ & & & $x$ & $x$ & $x$ & & & $x$ & & & & & \\
\hline Li and Cook [31] & 2002 & & & $x$ & & & $x$ & & & & $x$ & & $x$ & & & \\
\hline $\begin{array}{l}\text { Maksimyuk \& Chernyshenko } \\
\text { [41] }\end{array}$ & 1999 & & & $x$ & & & $x$ & & & & $x$ & & & & & \\
\hline Marketos [44] & 1963 & & & $x$ & & & $x$ & & & & & & & $x$ & & \\
\hline Mitkevich and Kul'kov [94] & 2006 & & & $x$ & & & $x$ & & & & & & & $x$ & & \\
\hline Murthy and Kiusalaas [61] & 1966 & & & & & & $x$ & $\mathrm{X}$ & & & & $x$ & & & & \\
\hline Papargyri-Pegiou [59] & 1995 & & $x$ & & & $x$ & $x$ & & $x$ & & $x$ & & & & & \\
\hline Papargyri-Pegiou [62] & 2005 & & $x$ & & & $x$ & & $x$ & & & $x$ & & & & & \\
\hline Papargyri-Pegiou et al. [58] & 2000 & & $x$ & & & $x$ & & $x$ & & & $x$ & & & & & \\
\hline
\end{tabular}




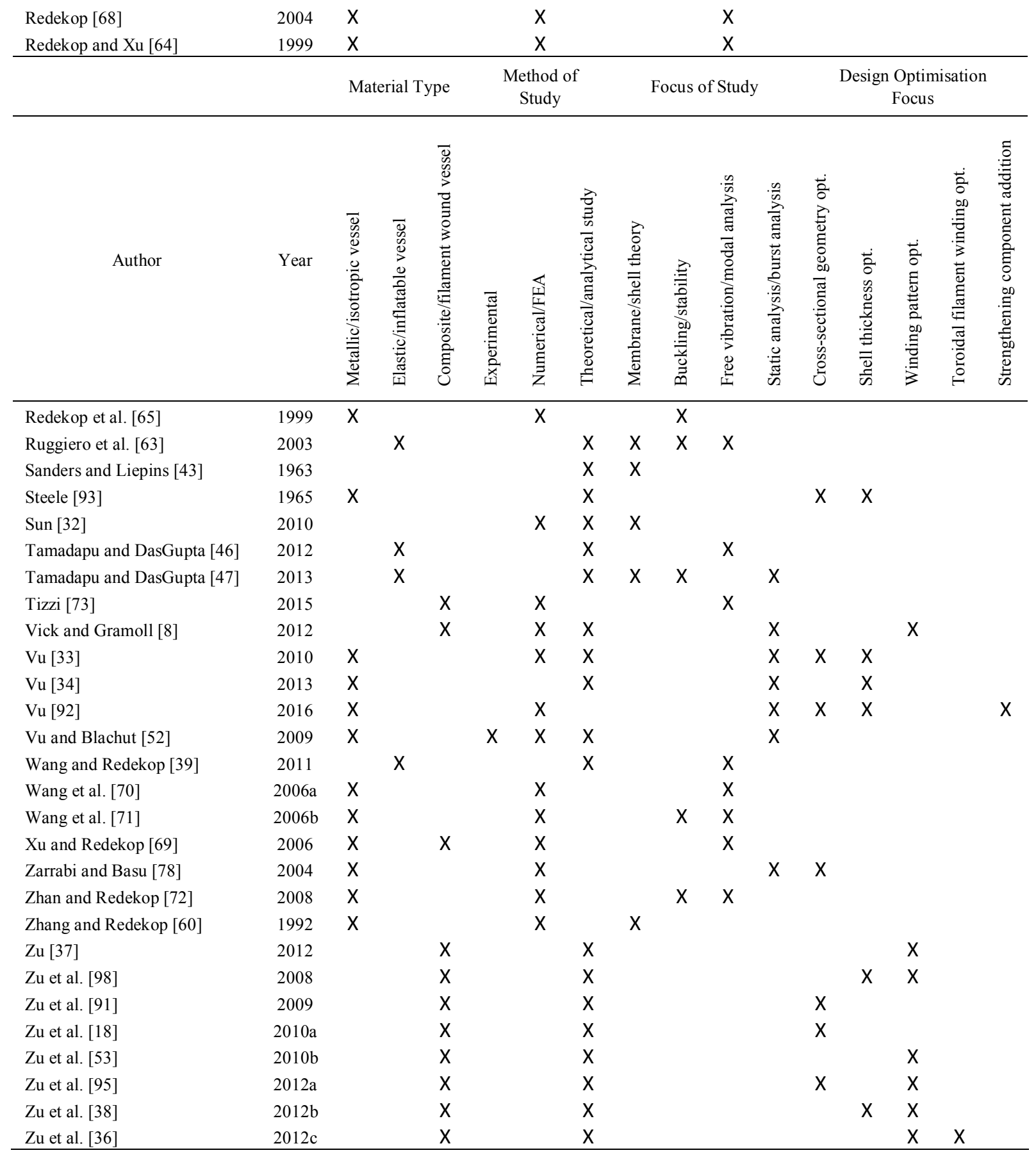

\section{References}

[1] Beer T, Grant T, Williams D, Watson H. Fuel-cycle greenhouse gas emissions from alternative fuels in Australian heavy vehicles. Atmospheric Environment 2002; 36(4): 753-763.

[2] Zheng JY, Liu XX, Xu P, Liu PF, Zhao YZ,Yang J. Development of high pressure gaseous hydrogen storage technologies. International Journal of Hydrogen Energy 2012; 37(1): 1048-1057.

[3] Sun BG, Zhang DS,Liu FS. Analysis of the cost-effectiveness of pressure for vehicular high-pressure gaseous hydrogen storage vessel. International Journal of Hydrogen Energy 2012; 37(17): 13088-13091.

[4] Barthelemy H. Hydrogen storage - industrial prospectives. International Journal of Hydrogen Energy 2012; 37(22): 1736417372.

[5] Ross DK. Hydrogen storage: The major technological barrier to the development of hydrogen fuel cell cars. Vacuum 2006; 80(10): 1084-1089. 
[6] Sarkar A,Banerjee R. Net energy analysis of hydrogen storage options. International Journal of Hydrogen Energy 2005; 30(8): $867-877$.

[7] Farzaneh-Gord M, Rahbari HR,Nikofard H. The effect of important parameters on the natural gas vehicles driving range. Polish Journal of Chemical Technology 2012; 14(4): 61-68.

[8] Vick MJ,Gramoll K. Finite element study on the optimization of an orthotropic composite toroidal shell. Journal of Pressure Vessel Technology - Transactions of the ASME 2012; 134(5): 051201-1 - 051201-7.

[9] Barthelemy H, Weber M,Barbier F. Hydrogen storage: Recent improvements and industrial perspectives. International Journal of Hydrogen Energy 2016

[10] Wahab MA, Alam MS, Pang SS, Peck JA,Jones RA. Stress analysis of non-conventional composite pipes. Composite Structures 2007; 79(1): 125-132.

[11] Hibbeler RC. Mechanics of Materials. 8th ed. Singapore: Prentice Hall, Pearson Eduction South Asia Pty Ltd; 2011.

[12] ISO 11439:2013 : Gas cylinders -- High pressure cylinders for the on-board storage of natural gas as a fuel for automotive vehicles. Geneva, Switzerland: International Standards Organisation (ISO), 2013.

[13] Liu PF, Chu JK, Hou SJ, Xu P,Zheng JY. Numerical simulation and optimal design for composite high-pressure hydrogen storage vessel: A review. Renewable \& Sustainable Energy Reviews 2012; 16(4): 1817-1827.

[14] Jaguar XJ8 (X308) 4.0 learns new tricks.... (Jaguar vehicle converted to LPG with toroidal storage tank), accessed 15 July 2015. Available: http://www.go-lpg.co.uk/X308.html

[15] Roh HS, Hua TQ,Ahluwalia RK. Optimization of carbon fiber usage in Type 4 hydrogen storage tanks for fuel cell automobiles. International Journal of Hydrogen Energy 2013; 38(29): 12795-12802.

[16] Önder A. First Failure Pressure of Composite Pressure Vessels. Masters Thesis, Graduate School of Natural and Applied Sciences, Dokuz Eylul University, Izmir, Turkey; 2007.

[17] Teng TL, Yu CM,Wu YY. Optimal design of filament-wound composite pressure vessels. Mechanics of Composite Materials 2005; 41(4): 333-340.

[18] Zu L, Koussios S,Beukers A. Optimal cross sections of filament-wound toroidal hydrogen storage vessels based on continuum lamination theory. International Journal of Hydrogen Energy 2010; 35(19): 10419-10429.

[19] $\mathrm{Zu} \mathrm{L}$, Koussios S,Beukers A. Integral design for filament-wound composite pressure vessels. Polymers \& Polymer Composites $2011 ; 19(4-5): 413-420$.

[20] Zu L, Koussios S,Beukers A. Design of filament-wound domes based on continuum theory and non-geodesic roving trajectories. Composites: Part A 2010; 41(9): 1312-1320.

[21] Vasiliev VV, Krikanov AA,Razin AF. New generation of filament-wound composite pressure vessels for commercial applications. Composite Structures 2003; 62(3-4): 449-459.

[22] Leh D, Saffré P, Francescato P,Arrieux R. Multi-sequence dome lay-up simulations for hydrogen hyper-bar composite pressure vessels. Composites Part A: Applied Science and Manufacturing 2013; 52: 106-117.

[23] Liang CC, Chen HW,Wang CH. Optimum design of dome contour for filament-wound composite pressure vessels based on a shape factor. Composite Structures 2002; 58(4): 469-482.

[24] Kim YS, Kim LH,Park JS. The effect of composite damage on fatigue life of the high pressure vessel for natural gas vehicles. Composite Structures 2011; 93(11): 2963-2968.

[25] De Miguel N, Acosta B, Moretto P,Ortiz Cebolla R. The effect of defueling rate on the temperature evolution of on-board hydrogen tanks. International Journal of Hydrogen Energy 2015; 40(42): 14768-14774.

[26] Heitsch M, Baraldi D,Moretto P. Numerical investigations on the fast filling of hydrogen tanks. International Journal of Hydrogen Energy 2011; 36(3): 2606-2612.

[27] Kim SC, Lee SH,Yoon KB. Thermal characteristics during hydrogen fueling process of type IV cylinder. International Journal of Hydrogen Energy 2010; 35(13): 6830-6835.

[28] Melideo D, Baraldi D, Galassi MC, Cebolla RO, Iborra BA,Moretto P. CFD model performance benchmark of fast filling simulations of hydrogen tanks with pre-cooling. International Journal of Hydrogen Energy 2014; 39(9): $4389-4395$.

[29] Zhao L, Liu YL, Yang JA, Zhao YZ, Zheng JY, Bie HY et al. Numerical simulation of temperature rise within hydrogen vehicle cylinder during refueling. International Journal of Hydrogen Energy 2010; 35(15): 8092-8100.

[30] Li QF, Zhou JQ, Chang Q,Xing W. Effects of geometry and inconstant mass flow rate on temperatures within a pressurized hydrogen cylinder during refueling. International Journal of Hydrogen Energy 2012; 37(7): 6043-6052.

[31] Li SG,Cook J. An analysis of filament overwound toroidal pressure vessels and optimum design of such structures. Journal of Pressure Vessel Technology-Transactions of the ASME 2002; 124(2): 215-222.

[32] Sun B. Closed-form solution of axisymmetric slender elastic toroidal shells. Journal of Engineering Mechanics 2010; 136(10): 1281-1288.

[33] Vu VT. Minimum weight design for toroidal pressure vessels using Differential Evolution and Particle Swarm Optimization. Structural and Multidisciplinary Optimization 2010; 42(3): 351-369.

[34] Vu VT. Optimum shape of constant stress toroidal shells. Journal of Pressure Vessel Technology - Transactions of the ASME 2013; 135(2): 024501-1 - 024501-4.

[35] $\mathrm{Hu} \mathrm{H}, \mathrm{Li} \mathrm{S}$, Wang J,Zu L. Structural design and experimental investigation on filament wound toroidal pressure vessels. 
[36] Zu L, Zhang DH, Xu YQ,Xiao DJ. Integral design and simulation of composite toroidal hydrogen storage tanks. International Journal of Hydrogen Energy 2012; 37(1): 1027-1036.

[37] Zu L. Stability of fiber trajectories for winding toroidal pressure vessels. Composite Structures 2012; 94(5): 1855-1860.

[38] Zu L, Koussios S,Beukers A. Minimum weight design of helically and hoop wound toroidal hydrogen storage tanks with variable slippage coefficients. Polymer Composites 2012; 33(12): 2218-2227.

[39] Wang XH,Redekop D. Free vibration analysis of moderately-thick and thick toroidal shells. Structural Engineering and Mechanics 2011; 39(4): 449-463.

[40] Adibi-Asl R. Elastic-plastic analysis of thick-walled toroidal pressure vessels. In Proceedings of the American Society of Mechanical Engineers, Pressure Vessels and Piping Division (Publication) PVP. Chicago, Illinois, U.S.A., 2008. p. 35-41.

[41] Maksimyuk VA,Chernyshenko IS. Nonlinear elastic state of thin-walled toroidal shells made of orthotropic composites. International Applied Mechanics 1999; 35(12): 1238-1245.

[42] Colbourne JR,Flugge W. The membrane theory of the toroidal shell - A singular perturbation problem. International Journal of Non-Linear Mechanics 1967; 2(1): 39-53.

[43] Sanders Jr. JL,Liepins AA. Toroidal membrane under internal pressure. AIAA Journal 1963; 1(9): 2105-2110.

[44] Marketos JD. Optimum toroidal pressure vessel filament wound along geodesic lines. AIAA Journal 1963; 1(8): 1942-1945.

[45] Kisioglu Y. Burst pressure determination of vehicle toroidal oval cross-section LPG fuel tanks. Journal of Pressure Vessel Technology - Transactions of the ASME 2011; 133(3): 031202-1 - 031202-5.

[46] Tamadapu G,DasGupta A. In-plane surface modes of an elastic toroidal membrane. International Journal of Engineering Science 2012; 60: 25-36.

[47] Tamadapu G,DasGupta A. Finite inflation analysis of a hyperelastic toroidal membrane of initially circular cross-section. International Journal of Non-Linear Mechanics 2013; 49: 31-39.

[48] Du Q, Cui W,Zhang B. Buckling characteristics of a circular toroidal shell with stiffened ribs. Ocean Engineering 2015; 108: 325-335.

[49] Du Q, Zou G, Zhang B,Wan Z. Simplified theoretical solution of circular toroidal shell with ribs under uniform external pressure. Thin-Walled Structures 2015; 96: 49-55.

[50] Geuskens FJJMM, Tielking JT, Koussios S,Beukers A. Modified linear-membrane formulation for the pressurized torus and multitorus. AIAA Journal 2013; 51(9): 2114-2125.

[51] Blachut J. Plastic loads for internally pressurized toroidal shells. Journal of Pressure Vessel Technology - Transactions of the ASME 2005; 127(2): 151-156.

[52] Vu VT,Blachut J. Plastic instability pressure of toroidal shells. Journal of Pressure Vessel Technology - Transactions of the ASME 2009; 131(5): 051203-1 - 051203-10.

[53] Zu L, Koussios S,Beukers A. Design of filament-wound circular toroidal hydrogen storage vessels based on non-geodesic fiber trajectories. International Journal of Hydrogen Energy 2010; 35(2): 660-670.

[54] Reddy JN. Theory and Analysis of Elastic Plates and Shells. Boca Raton, Florida, USA: CRC Press - Taylor \& Francis Group; 2007.

[55] Jordan PF. Stresses and deformations of the thin-walled pressurized torus. Journal of the Aerospace Sciences 1962; 29(2): 213225.

[56] Kydoniefs AD. The finite inflation of an elastic toroidal membrane. International Journal of Engineering Science 1967; 5(6): 477-494.

[57] Kydoniefs AD,Spencer AJM. The finite inflation of an elastic toroidal membrane of circular cross section. International Journal of Engineering Science 1967; 5(4): 367-391.

[58] Papargyri-Pegiou S,Stavrakakis E. Axisymmetric numerical solutions of a thin-walled pressurized torus of incompressible nonlinear elastic materials. Computers \& Structures 2000; 77(6): 747-757.

[59] Papargyri-Pegiou S. Stability of the axisymmetric analytical and numerical solutions in a thin-walled pressurized torus of compressible nonlinear elastic material. International Journal of Engineering Science 1995; 33(7): 1005-1025.

[60] Zhang F,Redekop D. Surface loading of a thin-walled toroidal shell. Computers and Structures 1992; 43(6): 1019-1028.

[61] Murthy MVV,Kiusalaas J. Toroidal-type shells free of bending under uniform normal pressure. Journal of The Franklin Institute - Engineering and Applied Mathematics 1966; 282(4): 232-241.

[62] Papargyri-Pegiou S. Finite-element analysis of an axisymmetric, thin-walled, nonlinear elastic pressurized torus. Acta Mechanica 2005; 178(1-2): 1-22.

[63] Ruggiero EJ, Jha A, Park G,Inman DJ. A literature review of ultra-light and inflated toroidal satellite components. Shock and Vibration Digest 2003; 35(3): 171-181.

[64] Redekop D,Xu B. Vibration analysis of toroidal panels using the differential quadrature method. Thin-Walled Structures 1999; 34(3): 217-231.

[65] Redekop D, Xu B,Zhang YM. Stability of a toroidal fluid-containing shell. International Journal of Pressure Vessels and Piping 1999; 76(9): 575-581.

[66] Jiang W,Redekop D. Polar axisymmetric vibration of a hollow toroid using the differential quadrature method. Journal of Sound 
[67] Jiang W,Redekop D. Static and vibration analysis of orthotropic toroidal shells of variable thickness by differential quadrature. Thin-Walled Structures 2003; 41(5): 461-478.

[68] Redekop D. Vibration analysis of a torus-cylinder shell assembly. Journal of Sound and Vibration 2004; 277(4-5): 919-930.

[69] $\mathrm{Xu}$ B,Redekop D. Natural frequencies of an orthotropic thin toroidal shell of elliptical cross-section. Journal of Sound and Vibration 2006; 293(1-2): 440-448.

[70] Wang XH, Xu B,Redekop D. Theoretical natural frequencies and mode shapes for thin and thick curved pipes and toroidal shells. Journal of Sound and Vibration 2006; 292(1-2): 424-434.

[71] Wang XH, Xu B,Redekop D. FEM free vibration and buckling analysis of stiffened toroidal shells. Thin-Walled Structures 2006; 44(1): 2-9.

[72] Zhan HJ,Redekop D. Vibration, buckling and collapse of ovaloid toroidal tanks. Thin-Walled Structures 2008; 46(4): $380-389$.

[73] Tizzi S. A free vibration analysis of toroidal composite shells in free space. Journal of Sound and Vibration 2015; 337: 116-134.

[74] Galletly GD. Elastic buckling of complete toroidal shells of elliptical cross-section subjected to uniform internal pressure. ThinWalled Structures 1998; 30(1-4): 23-34.

[75] Blachut J,Jaiswal OR. On buckling of toroidal shells under external pressure. Computers and Structures 2000; 77(3): $233-251$.

[76] Blachut J. Buckling and first ply failure of composite toroidal pressure hull. Computers and Structures 2004; 82(23-26): 19811992.

[77] Jones DP, Holliday JE,Larson LD. Elastic-plastic failure analysis of pressure burst tests of thin toroidal shells. Journal of Pressure Vessel Technology -Transactions of the ASME 1999; 121(2): 149-153.

[78] Zarrabi K,Basu A. Reference stress values for toroidal vessels subjected to uniform internal pressure. In Proceedings of the American Society of Mechanical Engineers, Pressure Vessels and Piping Division (Publication) PVP. San Diego, California, U.S.A., 2004. p. 33-37.

[79] Vasiliev VV. Chapter 2 - Filament Winding: Geometry, Mechanics and Manufacturing. In: R. M. Jones, editor. Composite Pressure Vessels: Analysis, Design and, Manufacturing. Blacksburg, VA, U.S.A.: Bull Ridge Publishing; 2009. p. $41-138$.

[80] De Carvalho J, Lossie M, Vandepitte D, Van Brussel H. Optimization of filament-wound parts based on non-geodesic winding. Composites Manufacturing 1995; 6(2): 79-84.

[81] Cook J, Chambers JK,Richards BJ, "Toroidal pressure vessels for breathing apparatus," presented at the Europe SAMPE Conference, Paris, France, 1998.

[82] Propulsion Systems: Pressurant and Propellant Tanks, accessed $14 \quad$ July. Available: http://www.sdcomposites.com/Products/p_product1.html

[83] Kuznetsov VM,Nekhoroshikh GE. Application of carbon fiber-reinforced plastics in the manufacture of toroidal pressure vessels. Polymer Science - Series D 2015; 8(3): 231-234.

[84] ISO/TS 15869:2009 : Gaseous hydrogen and hydrogen blends - Land vehicle fuel tanks. Geneva, Switzerland: International Standards Organisation (ISO), 2009.

[85] ANSI/CSA NGV2-2000. Basic Requirements for Compressed Natural Gas Vehicle (NGV) Fuel Containers. Cleveland, OH, U.S.A.: American National Standards Institute (ANSI)/CSA International, 2000.

[86] Blachut J. Collapse tests on externally pressurized toroids. Journal of Pressure Vessel Technology - Transactions of the ASME 2003; 125(1): 91-96.

[87] Flugge W. Stresses in Shells. 2nd ed.: Springer-Verlag Berlin Heidelberg; 1973.

[88] Sinclair GB,Helms JE. A review of simple formulae for elastic hoop stresses in cylindrical and spherical pressure vessels: What can be used when. International Journal of Pressure Vessels and Piping 2015; 128: 1-7.

[89] Bogomol'nyi VM,Zhidyaev NA. Optimization of the geometric parameters of elbows. Chemical and Petroleum Engineering 1992; 28(7): 418-420.

[90] Kishida M, Sasaki K, Machida M,San-Nohe T. Three-dimensional axisymmetric elastic stresses in hollow pressurized torus with varied thickness. The Japan Society of Mechanical Engineers (JSME) International Journal 1989; 32(1): 23-30.

[91] $\mathrm{Zu} \mathrm{L}$, Koussios S,Beukers A. Application of isotensoid-based cross sections to filament-wound toroidal pressure vessels. In Proceedings of the $17^{\text {th }}$ International Conference of Composite Materials (ICCM-17). Edinburgh, UK, 2009.

[92] Vu VT. Minimum weight design for toroidal shells with strengthening component. Journal of Pressure Vessel Technology Transactions of the ASME 2016; 138: 021202-1 - 021202-7.

[93] Steele CR. Toroidal pressure vessels. Journal of Spacecraft and Rockets 1965; 2(6): 937-943.

[94] Mitkevich AB,Kul'kov AA. Design optimization and forming methods for toroidal composite shells. Mechanics of Composite Materials 2006; 42(2): 95-108.

[95] Zu L, Koussios S,Beukers A. A novel design solution for improving the performance of composite toroidal hydrogen storage tanks. International Journal of Hydrogen Energy 2012; 37(19): 14343-14350.

[96] Park JS, Hong CS, Kim CG,Kim CU. Analysis of filament wound composite structures considering the change of winding angles through the thickness direction. Composite Structures 2002; 55(1): 63-71.

[97] ACG VTM260 Series Variable Temperature Moulding Prepreg System Datasheet: Advanced Composites Group Ltd, 2006.

[98] Zu L, Koussios S,Beukers A. Pattern design and optimization for filament-wound toroidal pressure vessels. In Proceedings of the 
23rd Technical Conference of the American Society for Composites. Memphis, TN, USA, 2008. p. 197-210.

[99] Gray A. Modern Differential Geometry of Curves and Surfaces. Boca Raton, Florida, U.S.A.: CRC Press; 1993.

[100] Soden PD, Kitching R,Tse PC. Experimental failure stresses for $\pm 55^{\circ}$ filament wound glass fibre reinforced plastic tubes under biaxial loads. Composites 1989; 20(2): 125-135.

[101] Parnas L,Katirci N. Design of fiber-reinforced composite pressure vessels under various loading conditions. Composite Structures 2002; 58(1): 83-95.

[102] Önder A, Sayman O, Dogan T,Tarakcioglu N. Burst failure load of composite pressure vessels. Composite Structures 2009; 89(1): 159-166.

[103] Vasiliev VV. Chapter 8 - Practical Design and Special Problems. In: R. M. Jones, editor. Composite Pressure Vessels: Analysis, Design and, Manufacturing. Blacksburg, VA, U.S.A.: Bull Ridge Publishing; 2009. p. 623-676.

[104] Soutis C,Curtis PT. Prediction of the post-impact compressive strength of CFRP laminated composites. Composites Science and Technology 1996; 56(6): 677-684.

[105] FMVSS 304. Compressed Natural Gas Fuel Container Integrity. Washington, DC, U.S.A.: National Highway Traffic Safety Administration, Office of Vehicle Safety Compliance, 2003.

[106] UN Regulation No. $110 \mid$ Compressed and Liquefied Natural Gas System Components vol. Addendum 109 - Regulation No. 110 , Revision 3, Amendment 1. Geneva, Switzerland: UNECE, 2014.

[107] ASME Boiler and Pressure Vessel Code, Section VIII Division 1, Pressure Vessels. New York: American Society of Mechanical Engineers (ASME), 1994.

[108] NFPA 52. Vehicular Gaseous Fuel Systems Code. Quincy, MA, U.S.A.: National Fire Protection Association (NFPA), 2010.

[109] Bourga R, Moore P, Janin YJ, Wang B,Sharples J. Leak-before-break: Global perspectives and procedures. International Journal of Pressure Vessels and Piping 2015; 129-130: 43-49.

[110] Han MG,Chang SH. Failure analysis of a Type III hydrogen pressure vessel under impact loading induced by free fall. Composite Structures 2015; 127: 288-297.

[111] Makinson J,Newhouse NL. Flaw testing of fiber reinforced composite pressure vessels. Journal of Pressure Vessel Technology 2014; 136(4): 041409-1 - 041409-5.

[112] Defense UDo. The Composite Materials Handbook-MIL 17: Guidelines for Characterization of Structural Materials vol. 1: CRC Press; 1999.

[113] Chen AS,Matthews FL. A review of multiaxial/biaxial loading tests for composite materials. Composites 1993; 24(5): 395-406.

[114] Whittingham B, Marshall IH, Mitrevski T,Jones R. The response of composite structures with pre-stress subject to low velocity impact damage. Composite Structures 2004; 66(1-4): 685-698.

[115] Mitrevski T, Marshall IH, Thomson RS,Jones R. Low-velocity impacts on preloaded GFRP specimens with various impactor shapes. Composite Structures 2006; 76(3): 209-217.

[116] Smits A, Van Hemelrijck D, Philippidis TP,Cardon A. Design of a cruciform specimen for biaxial testing of fibre reinforced composite laminates. Composites Science and Technology 2006; 66(7-8): 964-975.

[117] Lin WP,Hu HT. Parametric study on the failure of fiber-reinforced composite laminates under biaxial tensile load. Journal of Composite Materials 2002; 36(12): 1481-1503.

[118] D7136/D7136M-12: Standard Test Method for Measuring the Damage Resistance of a Fiber-Reinforced Polymer Matrix Composite to a Drop-Weight Impact Event. PA, U.S.A.: ASTM International, 2012.

[119] Wang SX, Wu LZ,Ma L. Low-velocity impact and residual tensile strength analysis to carbon fiber composite laminates. Materials \& Design 2010; 31(1): 118-125.

[120] Sjögren A, Krasnikovs A,Varna J. Experimental determination of elastic properties of impact damage in carbon fibre/epoxy laminates. Composites - Part A: Applied Science and Manufacturing 2001; 32(9): 1237-1242.

[121] Scarponi C, Briotti G, Barboni R,Marcone A. Reduction of tensile strength in angle-ply composite laminates due to low-velocity impact. Journal of Reinforced Plastics and Composites 1999; 18(1): 63-85.

[122] Zhao GP,Cho CD. Damage initiation and propagation in composite shells subjected to impact. Composite Structures 2007; 78(1): 91-100.

[123] Vaidya RS,Sun CT. Fracture criterion for notched thin composite laminates. AIAA Journal 1997; 35(2): 311-316.

[124] Carlsson LA, Aronsson CG,Bäcklund J. Notch sensitivity of thermoset and thermoplastic laminates loaded in tension. Journal of Materials Science 1989; 24(5): 1670-1682.

[125] Chiu ST, Liou YY, Chang YC,Ong CL. Low velocity impact behavior of prestressed composite laminates. Materials Chemistry and Physics 1997; 47(2-3): 268-272.

[126] Guillaud N, Froustey C, Dau F,Viot P. Impact response of thick composite plates under uniaxial tensile preloading. Composite Structures 2015; 121: 172-181.

[127] Heimbs S, Bergmann T, Schueler D,Toso-Pentecôte N. High velocity impact on preloaded composite plates. Composite Structures 2014; 111(1): 158-168.

[128] Johnson AF, Toso-Pentecôte N,Schueler D. Damage tolerance of pre-stressed composite panels under impact loads. Applied Composite Materials 2014; 21(1): 123-147.

[129] Kumazawa H, Susuki I, Hasegawa O,Kasano H. Influence of biaxial loads on impact fracture of high-strength membrane 
materials. Advanced Composite Materials 2009; 18(4): 395-413.

[130] Camara S, Bunsell AR, Thionnet A,Allen DH. Determination of lifetime probabilities of carbon fibre composite plates and pressure vessels for hydrogen storage. International Journal of Hydrogen Energy 2011; 36(10): 6031-6038.

[131] Berro Ramirez JP, Halm D, Grandidier JC,Villalonga S. A fixed directions damage model for composite materials dedicated to hyperbaric type IV hydrogen storage vessel - Part I: Model formulation and identification. International Journal of Hydrogen Energy 2015; 40(38): 13165-13173.

[132] Berro Ramirez JP, Halm D, Grandidier JC,Villalonga S. A fixed directions damage model for composite materials dedicated to hyperbaric type IV hydrogen storage vessel - Part II: Validation on notched structures. International Journal of Hydrogen Energy 2015; 40(38): 13174-13182.

[133] Berro Ramirez JP, Halm D, Grandidier JC, Villalonga S,Nony F. 700 bar type IV high pressure hydrogen storage vessel burst Simulation and experimental validation. International Journal of Hydrogen Energy 2015; 40(38): 13183-13192.

[134] Gentilleau B, Villalonga S, Nony F,Galiano H. A probabilistic damage behavior law for composite material dedicated to composite pressure vessel. International Journal of Hydrogen Energy 2015; 40(38): 13160-13164.

[135] Magneville B, Gentilleau B, Villalonga S, Nony F,Galiano H. Modeling, parameters identification and experimental validation of composite materials behavior law used in 700 bar type IV hydrogen high pressure storage vessel. International Journal of Hydrogen Energy 2015; 40(38): 13193-13205.

[136] Leh D, Saffré P, Francescato P, Arrieux R, Villalonga S. A progressive failure analysis of a 700-bar type IV hydrogen composite pressure vessel. International Journal of Hydrogen Energy 2015; 40(38): 13206-13214.

[137] Nimdum P, Patamaprohm B, Renard J,Villalonga S. Experimental method and numerical simulation demonstrate non-linear axial behaviour in composite filament wound pressure vessel due to thermal expansion effect. International Journal of Hydrogen Energy 2015; 40(38): 13231-13241.

[138] Berro Ramirez JP, Halm D, Grandidier JC, Villalonga S, Nony F. Experimental study of the thermomechanical behavior of wound notched structures. International Journal of Hydrogen Energy 2015; 40(38): 13148-13159. 